Check for updates

Cite this: J. Mater. Chem. C, 2021 9, 1287

Received 12th October 2020 ,

Accepted 4th December 2020

DOI: $10.1039 / \mathrm{d} 0 \mathrm{tc} 04839 a$

rsc.li/materials-c

\section{Synthesis, mesomorphism, photophysics and device performance of liquid-crystalline pincer complexes of gold(III) $\dagger$}

\author{
Rachel R. Parker, (D) ${ }^{a}$ Denghui Liu, ${ }^{b}$ Xiankang Yu, ${ }^{b}$ Adrian C. Whitwood, (D) a \\ Weiguo Zhu, (D) ${ }^{b}$ J. A. Gareth Williams, (D)*c Yafei Wang, (D) *b Jason M. Lynam (D)*a \\ and Duncan W. Bruce (D)*a
}

\begin{abstract}
Emissive gold(III) complexes of pincer 2,6-diphenylpyridines also bearing a phenylacetylide ligand have been modified at both the pincer and phenylacetylide to confer liquid crystalline properties, with most complexes showing a columnar hexagonal phase in the condensed phase. Solution NMR studies show a preferred orientation for self-association, consistent with structural parameters in the liquid crystal phase obtained by X-ray methods. While the pattern of substitution of the phenylacetylide has no discernible effect on the photophysics, when two alkoxy chains are attached to the pincer ligands, photoluminescence quantum yields (PLQY) of around 3\% are found, whereas when four alkoxy chains are attached the PLQY increases significantly to $36 \%$. Insight from computational chemistry indicated that the incorporation of the alkoxy donor groups raises the energy of the pincer-based HOMO-1 orbital, with a concomitant lowering of the LUMO $\leftarrow$ HOMO-1 transition energy, consistent with an experimentally observed red shift. The gold complexes were fabricated into OLED devices using solution processing methods, being doped into the emissive layer at $5 \%$, leading to external quantum efficiencies of up to $7.14 \%$, values that compare well with those of related complexes in the literature.
\end{abstract}

\section{Introduction}

Luminescent metallomesogens, which combine the properties of self-organisation and emissive behaviour, have potential applications in the field of semiconductors and are known in the literature. ${ }^{1}$ Most of these studies have been based on complexes of platinum(II), ${ }^{2-6}$ which is amenable to liquid crystal phase formation on the basis of its square-planar geometry, but there have also been reports based on, for example, gallium(III), ${ }^{7}$ zinc(II), ${ }^{8,9}$ silver(I), ${ }^{10}$ various lanthanides ${ }^{11}$ and iridium(III), ${ }^{12-17}$ the last two of which are somewhat more challenging given the $3 \mathrm{D}$, octahedral nature of the metal centre. One attraction of phosphorescent metallomesogens relates to taking advantage of the long-range order possible in liquid crystal systems to generate ordered conduction layers, so potentially reducing drive

\footnotetext{
${ }^{a}$ Department of Chemistry, University of York, Heslington, York YO10 5DD, UK. E-mail: duncan.bruce@york.ac.uk; Tel: +44 (0)1904 324085

${ }^{b}$ School of Materials Science \& Engineering, Changzhou University, Changzhou 213164, P. R. China. E-mail: qiji830404@hotmail.com ${ }^{c}$ Department of Chemistry, Durham University, University Science Laboratories, South Road, Durham DH1 3LE, UK

$\dagger$ Electronic supplementary information (ESI) available. CCDC 1991483-1991485. For ESI and crystallographic data in CIF or other electronic format see DOI: 10.1039/d0tc04839a
}

voltages. In addition, for rod-like molecules, one of the attractive goals is to use the order of nematic or SmA phases to realise polarised emission, which has been demonstrated in fluorescent materials $^{18}$ with some reports also for phosphorescent systems. ${ }^{19}$

Gold(III) compounds have started to attract attention due to their application in semiconductors and to their interesting photophysical properties. Much of this interest arose from the report by Yam et al. of room-temperature phosphorescence in gold(III) complexes containing a CNC pincer ligand and a phenylacetylide in the fourth coordination site (Chart 1) that began to focus interest in these materials. ${ }^{20}$ As the acetylide ligand is a strong $\sigma$-donor, the d-orbital splitting increases when compared to the halide analogues, so that the evidence from vibronic progression in both absorption and emission spectra shows the chromophore to be based on the pincer ligand, with effectively no influence of the acetylide.

Using this observation as a base, numerous analogues have been prepared ${ }^{21-46}$ and solution PLQY values for triplet emission in acetylide derivatives of up to $61 \%$ have been reported. ${ }^{26}$ More recently values of up to $94 \%$ have been recorded based on singlet emission by TADF from gold(III) complexes with tetradentate ligands, ${ }^{47,48}$ while in solution-processed devices, external quantum efficiencies (EQE) of $15-16 \%$ have been achieved. ${ }^{28,49}$ 


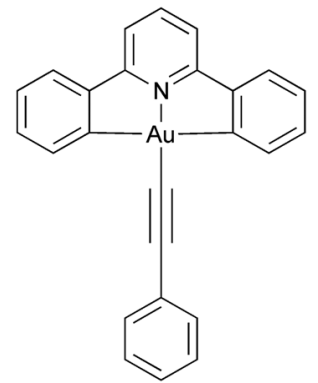

Chart 1 Parent phosphorescent gold(III) chromophore as reported by Yam et al. ${ }^{20}$

More recently, Li et al. considered design strategies that address both thermal stability and photophysical efficiency of complexes of this general type. Based on isomeric CCN pincer ligands with carbazole donor ligands, they have reported EQE values of up to $11.9 \%$ for devices constructed using solution processing, which rise to $21.6 \%$ if vacuum deposition is employed. In both cases, the devices show long operational half-lives. ${ }^{50}$

Given the increasing interest in the gold(III) system just described and our previous experience with phosphorescent liquid crystals, we have undertaken a study that encompasses the design and synthesis of emissive liquid-crystalline complexes of gold(III) as well as an evaluation of their photophysical response and their performance in solution-processed OLEDs. To the best of our knowledge, the vast majority of known gold-based liquid-crystalline materials ${ }^{51,52}$ are linear and based on $\mathrm{Au}(\mathrm{I})$ with a $\mathrm{C}-\mathrm{Au}-\mathrm{X}$ or $\mathrm{C}-\mathrm{Au}-\mathrm{C}$ skeleton. As such, the materials reported here represent a new family of metallomesogens and present an opportunity to develop an understanding of the relationship between the molecular structure of the complexes and both liquid crystal and emission properties. In this contribution, we now report a series of gold(III) complexes which, by virtue of modified pincer and acetylide ligands, exhibit liquid crystalline properties. The effects of different ligand substitution patterns on the photophysical properties of the complexes are described, notably the raising in energy of the pincer-based HOMO on incorporation of alkoxy groups. Device data demonstrate that the complexes exhibit an EQE of up to $7.14 \%$.

\section{Synthesis}

The target compounds have two principal components, the tridentate, pincer-like CNC 'backbone' and the monodentate acetylide ligand. The pincer proligands were readily prepared by coupling a mono- or di-methoxyphenylboronic acid with 2,6dibromopyridine using a Suzuki-Miyaura protocol (Scheme 1, step (i)). The bis(methoxyphenyl)pyridine and bis(dimethoxyphenyl) pyridine products, $\mathbf{1}$, were demethylated using molten pyridinium chloride to give 2 , after which a Williamson ether reaction of the phenolic or catecholic product with 1-bromododecane furnished<smiles>COc1ccc([18OH])cc1C</smiles><smiles>[2H]c1cc(-c2cccc(-c3ccc(OC)c(P)c3)n2)ccc1OC</smiles>

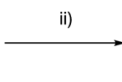<smiles>[2H]c1cc(-c2cccc(-c3ccc(O)c(P)c3)n2)ccc1O</smiles>

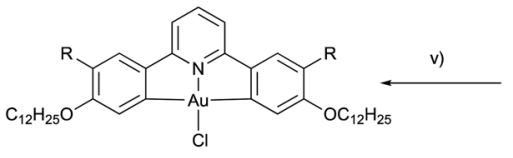<smiles>[R]c1cc(-c2cccc(-c3cc([R])c(OCC)cc3OCC)n2)ccc1OCC</smiles><smiles>[2H]c1cc(-c2cccc(-c3ccc(OCCC)c(P)c3)n2)ccc1OCC</smiles>
$5 \mathrm{R}=\mathrm{H}$
$14 \mathrm{R}=\mathrm{OC}_{12} \mathrm{H}_{25}$ (vi)

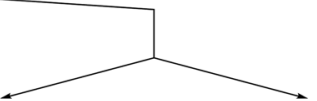

$4 \mathrm{R}=\mathrm{H}$ or $\mathrm{OC}_{12} \mathrm{H}_{25}$ $3 \mathrm{R}=\mathrm{H}$ or $\mathrm{OC}_{12} \mathrm{H}_{25}$

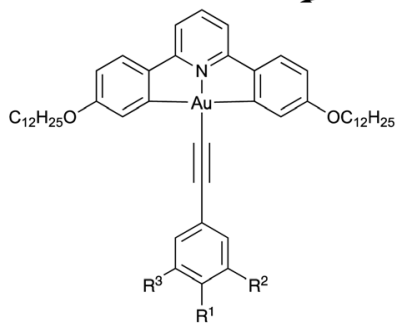

6-a-c $R^{1}=\mathrm{H}, \mathrm{C}_{5} \mathrm{H}_{11}, \mathrm{C}_{8} \mathrm{H}_{17} ; \mathrm{R}^{2}=\mathrm{R}^{3}=\mathrm{H}$ 7-a-d $\mathrm{R}^{1}=\mathrm{OC}_{n} \mathrm{H}_{2 n+1} ; \mathrm{R}^{2}=\mathrm{R}^{3}=\mathrm{H}$ 8-a-d $\mathrm{R}^{1}=\mathrm{R}^{2}=\mathrm{OC}_{n} \mathrm{H}_{2 n+1} ; \mathrm{R}^{3}=\mathrm{H}$ 9-a-d $R^{1}=R^{2}=R^{3}=O C_{n} H_{2 n+1}$

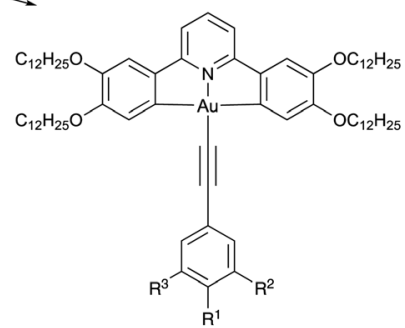

10-a-c $R^{1}=\mathrm{H}, \mathrm{C}_{5} \mathrm{H}_{11}, \mathrm{C}_{8} \mathrm{H}_{17} ; \mathrm{R}^{2}=\mathrm{R}^{3}=\mathrm{H}$

11-a-d $\mathrm{R}^{1}=\mathrm{OC}_{n} \mathrm{H}_{2 n+1} ; \mathrm{R}^{2}=\mathrm{R}^{3}=\mathrm{H}$ 12-a-d $\mathrm{R}^{1}=\mathrm{R}^{2}=\mathrm{OC}_{n} \mathrm{H}_{2 n+1} ; \mathrm{R}^{3}=\mathrm{H}$
13-a-d $\mathrm{R}^{1}=\mathrm{R}^{2}=\mathrm{R}^{3}=O \mathrm{CC}_{n} \mathrm{H}_{2 n+1}$

For 7-9 and 11-13:
a: $n=8 ;$ b: $n=10 ;$ c: $n=12 ; \mathrm{d}: n=14$

Scheme 1 Synthetic route to the target complexes: (i) $\left[\mathrm{Pd}_{3}(\mathrm{OAc})_{6}\right] / \mathrm{K}_{3} \mathrm{PO}_{4} / \mathrm{HOCH}_{2} \mathrm{CH}_{2} \mathrm{OH}$; (ii) $\mathrm{pyH}^{+} \mathrm{Cl}^{-} / \Delta$; (iii) $\mathrm{C}_{12} \mathrm{H}_{25} \mathrm{Br} / \mathrm{K}_{2} \mathrm{CO} 3 / \mathrm{DMF}$; (iv) (a) $\mathrm{Hg}$ (OAc) $/$

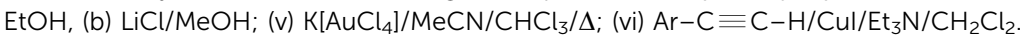




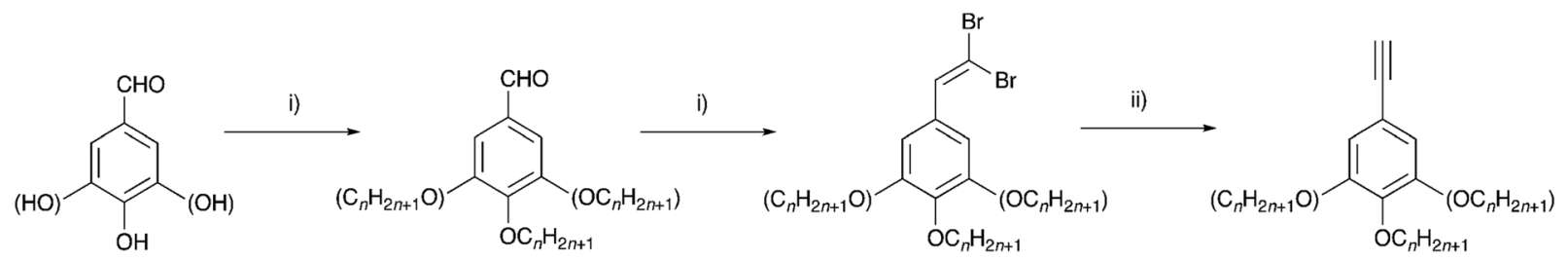

Scheme 2 Synthetic route to the phenylacetylenes: (i) $\mathrm{CBr}_{4} / \mathrm{PPh}_{3} / \mathrm{CH}_{2} \mathrm{Cl}_{2}$; (ii) (a) $\mathrm{EtMgBr}$ in $\mathrm{THF}$, (b) $\mathrm{NH}_{4} \mathrm{Cl}$.

the desired ligands. Smooth, high-yielding auration of such ligands is only possible when they are first reacted with mercury(II) acetate to give a cyclomercurated intermediate $\mathbf{4}$, from which transmetallation with tetrachloroaurate(III) yielded the chlorogold(III)-CNC complex, with a yield over two steps of $26 \%$ for 5 and $13 \%$ for 14. ${ }^{53}$ The required mono-, di- or -tri-alkoxyphenyl-substituted alkynes were prepared from the corresponding benzaldehyde using a Corey-Fuchs protocol (Scheme 2). In the case of 4alkoxyphenylbenzaldehyde and 3,4-dialkoxybenzaldehyde, the precursors were the simple hydroxy analogues, whereas 3,4,5trialkoxyphenylbenzaldehyde was obtained starting from methyl 3,4,5-trihydroxybenzoate wherein the ester was reduced to the benzyl alcohol before being re-oxidised to the aldehyde. The gold acetylides were prepared by the copper-mediated metathesis of the chloro ligand of complexes $\mathbf{5}$ and $\mathbf{1 4}$ with the alkyne (Scheme 1, step (vi)). Using this approach, a family of 26 new complexes

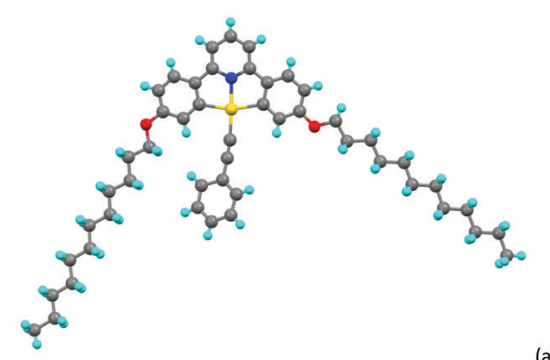

(a)

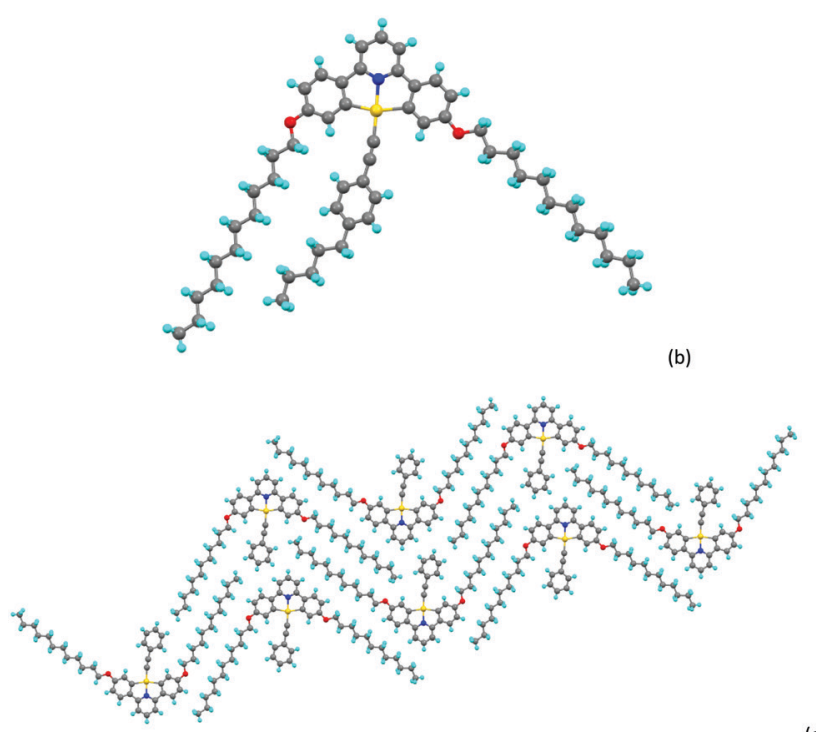

(c)

Chart 2 (a) Molecular structure of complex $\mathbf{6 a}$, (b) molecular structure of complex $\mathbf{6 b}$, (c) packing of complex $\mathbf{6 a}$. (including two further complexes incorporating 4-ethynylpyridine as the monodentate ligand) was obtained.

\section{X-ray single crystal structures of $5,6 a$ and $6 \mathrm{~b}$}

For complexes $5, \mathbf{6 a}$ and $\mathbf{6 b}$ it was possible to obtain crystals of sufficient quality to allow structure determination by X-ray methods and the crystallographic data are compiled in Table S1 (ESI $\dagger$ ). A brief description of the structure of 5 is given in the ESI, $\dagger$ while those of $\mathbf{6 a}$ and $\mathbf{6 b}$ are described here. In both complexes (Chart 2), the gold sits in an approximately square planar environment where, for example in $\mathbf{6 a}$, the $\mathrm{C}-\mathrm{Au}-\mathrm{C}$ angles within the pincer ligand are $162.7(3)^{\circ}$ and the $\mathrm{N}-\mathrm{Au}-\mathrm{C}$ angles are about $177.6(3)^{\circ}$. There is also a small bend in the acetylenic bond such that the $\mathrm{Au}-\mathrm{C}-\mathrm{C}$ angle is $173.2(6)^{\circ}$, the reason for which appears evident when packing is taken into consideration. As shown in Chart $2 \mathrm{c}$ there is an interdigitation of the alkyl chains which apparently enables the space to one side of the phenylacetylide to be filled by a second molecule of complex (Chart $2 \mathrm{c}$ ).

\section{Solution studies by NMR spectroscopy}

Luminescent gold-acetylide prone to aggregation (e.g. through gel formation) have been studied in solution by NMR spectroscopy at various concentrations, predominantly by Yam and co-workers, with many of these studies being of complexes bearing a 3,4,5-trialkoxyphenylacetylide co-ligand. ${ }^{42-44}$ Similar

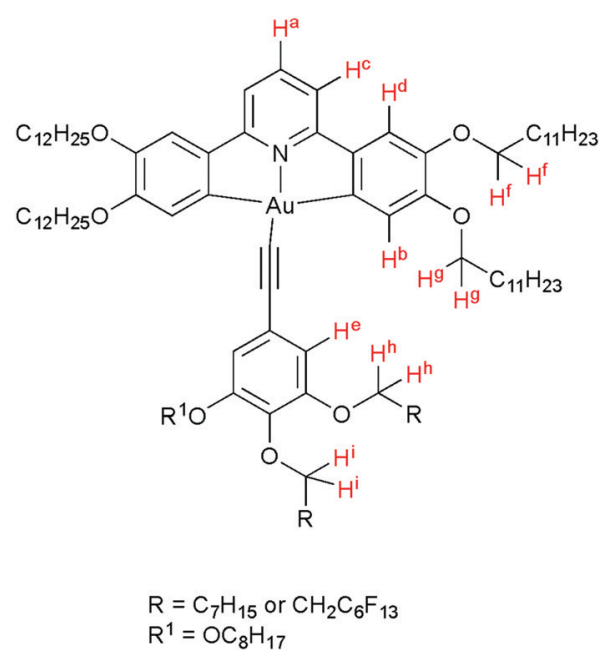

Fig. 1 Structure of 13a, showing the labelling system for the $\mathrm{H}$-atoms. 


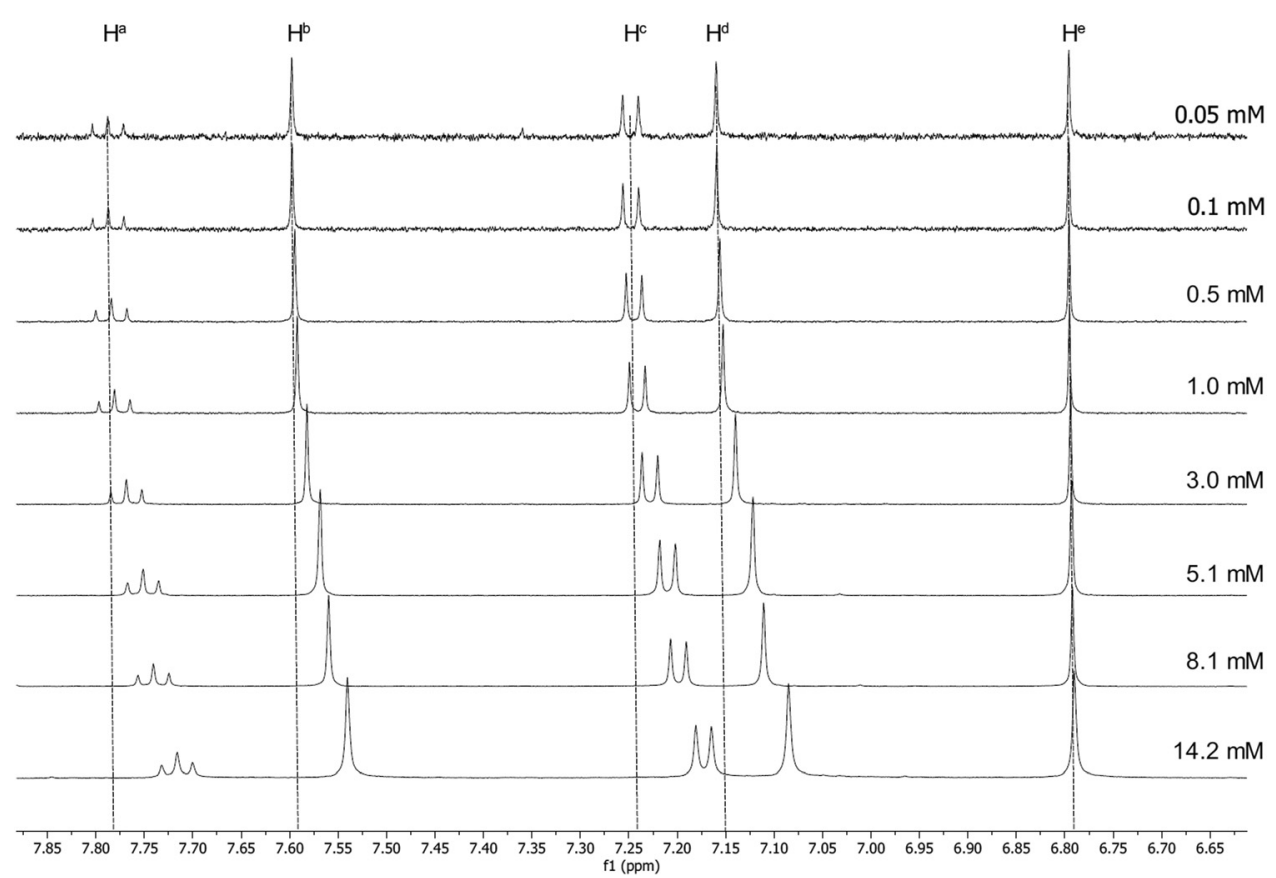

Fig. $2{ }^{1} \mathrm{H}$ NMR spectra of 13a at increasing concentration in $\mathrm{CD}_{2} \mathrm{Cl}_{2}$, showing the downfield shift of the aromatic protons on the pincer ligand.

effects have been observed by Suleymanova et al. for a cyclometallated platinum(II) complex studied by both ${ }^{1} \mathrm{H}$ and ${ }^{195} \mathrm{Pt}$ NMR spectroscopy. ${ }^{54}$ In order to quantify this effect to determine if the aggregation might influence the photophysical properties of these complexes, rigorous, concentration-dependent studies of 13a were undertaken by ${ }^{1} \mathrm{H}$ NMR and electronic spectroscopies. The labelling of the hydrogen atoms in this complex is shown in Fig. 1.
The ${ }^{1} \mathrm{H}$ NMR spectra for 13a recorded in $\mathrm{CD}_{2} \mathrm{Cl}_{2}$ at a range of concentrations are shown in Fig. 2 and 3. A downfield shift is observed for the aromatic protons on the pincer ligand $\left(\mathrm{H}^{\mathrm{a}}, \mathrm{H}^{\mathrm{b}}\right.$, $\mathrm{H}^{\mathrm{c}}$ and $\mathrm{H}^{\mathrm{d}}$ ) with decreasing concentration. The absolute change in the chemical shift is small, with $\Delta \delta$ approximately $0.07-$ $0.06 \mathrm{ppm}$ on increasing the concentration from $5.0 \times 10^{-5} \mathrm{mmol}$ to $1.4 \times 10^{-2} \mathrm{mmol}$; nevertheless, the trend over this concentration

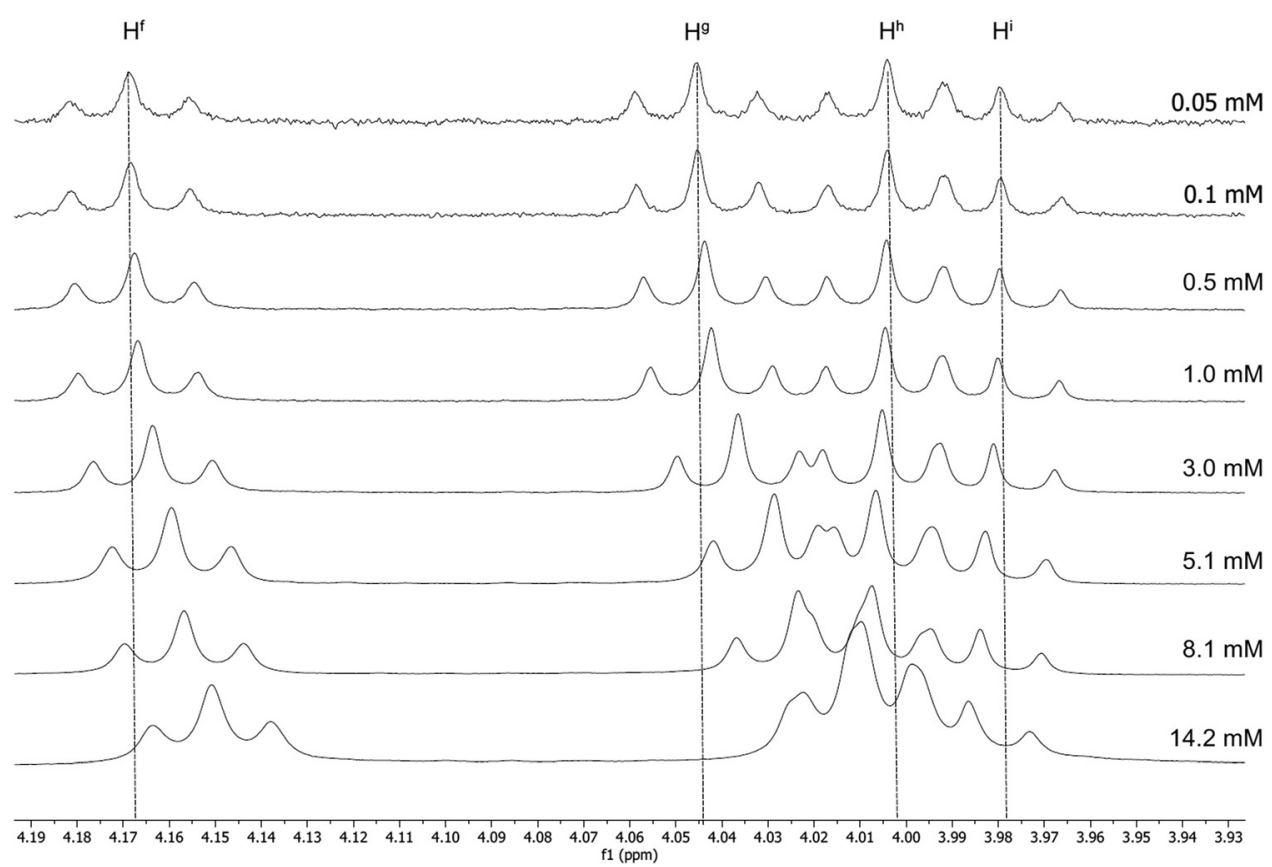

Fig. $3{ }^{1} \mathrm{H}$ NMR spectra of 13a at increasing concentrations in $\mathrm{CD}_{2} \mathrm{Cl}_{2}$, showing the change in the chemical shift of the O-CH2 hydrogen atoms of the alkyl chains on both ring systems. 


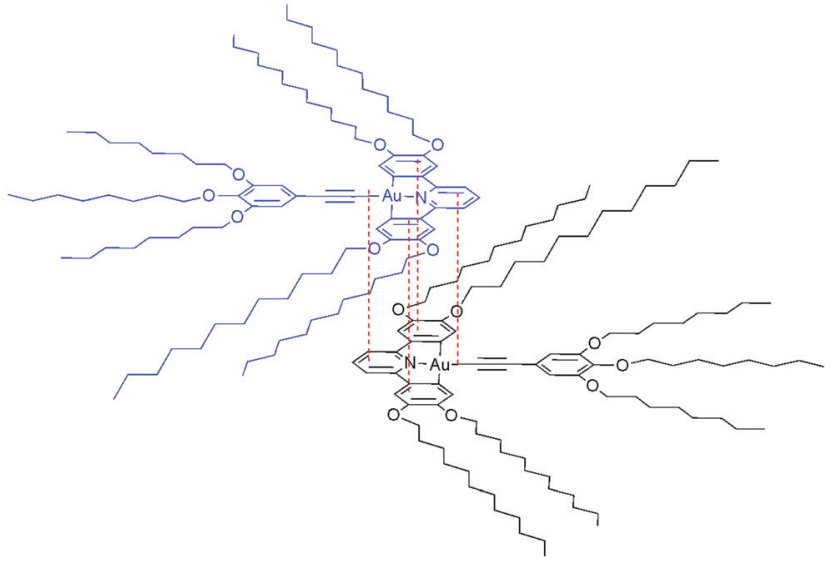

Fig. 4 Proposed aggregate of $13 a$ in concentrated solution showing a 'back-to-back' dimer formed through interfacial interactions. Relative distances are exaggerated for clarity.

range is clear (Fig. 2). A similar trend is also observed in the resonances for the $\mathrm{O}-\mathrm{CH}_{2}$ protons of the alkyl chains on the cyclometallating ring, $\mathrm{H}^{\mathrm{f}}$ and $\mathrm{H}^{\mathrm{g}}$ (Fig. 3), although the shifts were smaller with $\Delta \delta$ between 0.02 and $0.04 \mathrm{ppm}$.

These data are consistent with a 'back-to-back' self-assembly in solution where there is overlap of the rigid aromatic cores of the complex, resulting in a shielding of the protons of the $\mathrm{C}^{\wedge} \mathrm{N}^{\wedge} \mathrm{C}$ ligand, and where the phenylalkynyl moiety is free of associations (Fig. 4). Similar self-association has been postulated previously in a number of systems. ${ }^{20,55}$

The resonances for the acetylide ligand showed only a very small and opposite shift $\left(\mathrm{H}^{\mathrm{h}}\right.$ and $\left.\mathrm{H}^{\mathrm{i}}\right)$ or no concentration dependence $\left(\mathrm{H}^{\mathrm{e}}\right)$. This would appear to indicate that any intermolecular process involving this region of the complex is different from that mediated by the $\mathrm{C}^{\wedge} \mathrm{N}^{\wedge} \mathrm{C}$ ligands.

Consideration of the data in Fig. 2 and 3 shows clearly that the change in chemical shift ceases as the concentration decreases below approximately $1 \times 10^{-4} \mathrm{M}$. Electronic spectroscopy below this concentration regime (see below) shows no change in the absorption profile, positions of maxima, or molar extinction coefficients for any of the observed transitions, nor the appearance of any new absorption bands. This is consistent with the lack of change in the ${ }^{1} \mathrm{H}$ NMR spectra and therefore under these dilute conditions the extent of aggregation is minimal.

\section{Liquid-crystalline behaviour of the new complexes}

The liquid crystal properties of the new complexes were studied using polarised optical microscopy, differential scanning calorimetry (DSC) and small-angle X-ray scattering (SAXS). They are considered first as two groups - with two (5 to 9) and then with four (10 to 13) terminal chains on the pincer ligand.

Complexes with two terminal chains on the pincer ligand (5 to 9)

The transition temperatures for complexes $\mathbf{5}$ to $\mathbf{9}$ are given in Table 1, while the SAXS data are collected in Table S2 (ESI $\dagger$ ).
Table 1 Transition temperatures and enthalpies of complexes $\mathbf{5}$ to $\mathbf{9}$, featuring two chains on the CNC ligand

\begin{tabular}{|c|c|c|c|}
\hline Complex & Transition $^{c}$ & $T\left({ }^{\circ} \mathrm{C}\right)$ & $\Delta H\left(\mathrm{~kJ} \mathrm{~mol}^{-1}\right)$ \\
\hline \multirow[t]{2}{*}{5} & Cr-Lam & 91.9 & 37.4 \\
\hline & Lam-Iso & 159.8 & 28.6 \\
\hline $6 \mathbf{a}$ & Cr-Iso & 71.2 & 57.2 \\
\hline \multirow[t]{3}{*}{$6 \mathbf{b}$} & $\mathrm{Cr}-\mathrm{Cr}^{\prime}$ & 45.3 & 1.9 \\
\hline & $\mathrm{Cr}^{\prime}-\mathrm{Cr}^{\prime \prime}$ & 53.3 & 12.0 \\
\hline & $\mathrm{Cr}^{\prime \prime}$-Iso & 68.2 & 8.2 \\
\hline \multirow[t]{2}{*}{$6 c$} & $\mathrm{Cr}-\mathrm{Col}_{\mathrm{h}}$ & 57.0 & 16.3 \\
\hline & $\mathrm{Col}_{\mathrm{h}}$-Iso & 69.0 & 1.7 \\
\hline \multirow[t]{2}{*}{$7 a$} & Cr-Iso & 101.8 & 38.2 \\
\hline & $\left(\right.$ Iso-Col $\left._{\mathrm{h}}\right)$ & $(90.6)$ & $(3.6)$ \\
\hline $7 \mathbf{b}$ & Cr-Iso & 102.5 & 32.2 \\
\hline $7 \mathrm{c}$ & Cr-Iso & 95.9 & 34.8 \\
\hline $7 d$ & Cr-Iso & 101.8 & 34.4 \\
\hline \multirow{3}{*}{$8 a$} & $\mathrm{Cr}-\mathrm{Cr}$ & 67.2 & 12.3 \\
\hline & $\mathrm{Cr}-\mathrm{Col}_{\mathrm{h}}$ & 75.7 & 45.3 \\
\hline & $\mathrm{Col}_{\mathrm{h}}-\mathrm{I}$ & 103.8 & 5.3 \\
\hline \multirow[t]{4}{*}{$8 b$} & $\mathrm{Cr}-\mathrm{Cr}$ & 71.8 & 7.9 \\
\hline & $\mathrm{Cr}-\mathrm{Col}_{\mathrm{h} 1}$ & 77.9 & 39.1 \\
\hline & $\mathrm{Col}_{\mathrm{h} 1}$-Iso & 104.9 & 5.8 \\
\hline & $\left(\mathrm{Col}_{\mathrm{h} 2}-\mathrm{Col}_{\mathrm{h} 1}\right)$ & $(50.6)$ & $(1.2)$ \\
\hline \multirow[t]{2}{*}{$8 c$} & $\mathrm{Cr}-\mathrm{Col}_{\mathrm{h}}{ }^{b}$ & 77.5 & 40.0 \\
\hline & $\mathrm{Col}_{\mathrm{h}}$-Iso & 101.8 & 3.9 \\
\hline \multirow[t]{3}{*}{$8 d$} & $\mathrm{Cr}-\mathrm{Cr}^{\prime}$ & 74.9 & 21.3 \\
\hline & $\mathrm{Cr}^{\prime}-\mathrm{Col}_{\mathrm{h}}$ & 82.8 & 7.2 \\
\hline & $\mathrm{Col}_{\mathrm{h}}-\mathrm{I}$ & 100.1 & 3.9 \\
\hline \multirow[t]{2}{*}{$9 a$} & $\mathrm{Cr}-\mathrm{Col}_{\mathrm{r}}$ & 55.0 & 3.9 \\
\hline & $\mathrm{Col}_{\mathrm{r}}-\mathrm{I}$ & 80.7 & 22.9 \\
\hline \multirow[t]{4}{*}{$9 b$} & $\mathrm{Cr}-\mathrm{Cr}$ & 64.6 & 1.3 \\
\hline & $\mathrm{Cr}-\mathrm{Col}_{\mathrm{r}}$ & 79.8 & 13.9 \\
\hline & $\mathrm{Col}_{\mathrm{r}}-\mathrm{Col}_{\mathrm{h}}$ & $88.3^{a}$ & $5.7^{a}$ \\
\hline & $\mathrm{Col}_{\mathrm{h}}-\mathrm{I}$ & $96.7^{a}$ & $2.9^{a}$ \\
\hline \multirow[t]{4}{*}{$9 c$} & $\mathrm{Cr}-\mathrm{Cr}$ & 57.8 & 0.8 \\
\hline & $\mathrm{Cr}-\mathrm{Col}_{\mathrm{r}}$ & 78.1 & 16.9 \\
\hline & $\mathrm{Col}_{\mathrm{r}}-\mathrm{Col}_{\mathrm{h}}$ & 95.7 & 32.7 \\
\hline & $\mathrm{Col}_{\mathrm{h}}$-Iso & 102.1 & - \\
\hline \multirow[t]{4}{*}{ 9d } & $\mathrm{Cr}-\mathrm{Cr}$ & 52.7 & 2.2 \\
\hline & $\mathrm{Cr}-\mathrm{Col}_{\mathrm{h}}$ & 77.9 & 53.4 \\
\hline & $\mathrm{Col}_{\mathrm{h}}$-Iso & 88.0 & 3.0 \\
\hline & $\left(\mathrm{Col}_{\mathrm{h}}-\mathrm{Col}_{\mathrm{r}}\right)$ & $(77.8)$ & $(2.9)$ \\
\hline
\end{tabular}

${ }^{a}$ Observed on second heating cycle. ${ }^{b}$ Overlapping $\mathrm{Cr}-\mathrm{Cr}$ and $\mathrm{Cr}-\mathrm{Col}_{\mathrm{h}}$ peaks. ${ }^{c} \mathrm{Cr}=$ crystal; Iso = isotropic fluid; Lam = lamellar; $\mathrm{Col}_{\mathrm{h}}-$ hexagonal columnar phase.

Complex 5 shows an ordered lamellar phase between 91.9 and 159.8 ${ }^{\circ} \mathrm{C}$ as identified by SAXS data ( $d$-spacing of $30.7 \AA$, Fig. S3a, ESI $\dagger$ ), with microscopy showing a texture lacking in identifiable defects (Fig. S3b, ESI $\dagger$ ). A broad and weak reflection at $8.9 \AA$ was assigned tentatively as a gold-gold separation, but the presence of several other wide-angle reflections most likely indicates a degree of order in the phase consistent with crystalline order, a conclusion supported by the large clearing enthalpy of $26.8 \mathrm{~kJ} \mathrm{~mol}^{-1}$.

Of complexes 6 and 7, only $\mathbf{6 c}$ and $7 \mathbf{a}$ show a mesophase $\left(\mathrm{Col}_{\mathrm{h}}\right)$, which is enantiotropic in the former and monotropic in the latter, although interestingly it is more stable in 7a than in 6c. However, when the coverage of the $2 \mathrm{D}$ surface of the complex increases with two (8) or three (9) terminal chains on the phenylacetylide, then all of the complexes show enantiotropic $\mathrm{Col}_{\mathrm{h}}$ and/or $\mathrm{Col}_{\mathrm{r}}$ phases. In general, the phases of these complexes did not give rise to good optical textures and in several cases the SAXS data did not show the higher-order reflections that would confirm the identity (Fig. S4, ESI $\dagger$ ). 


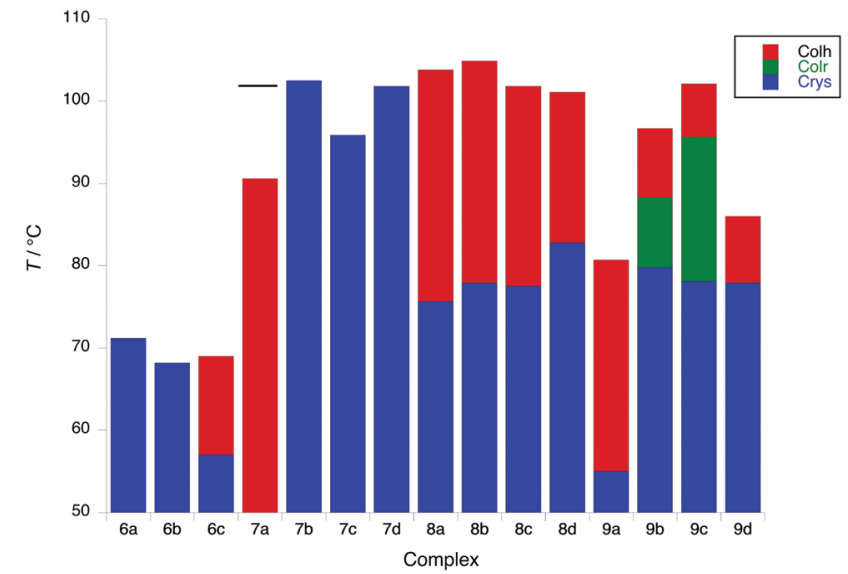

Fig. 5 Transition temperatures and phases for $\mathbf{6}$ to 8 ; the melting point of $7 \mathrm{a}$ is shown as a black bar (phase is monotropic).

In these cases, it was necessary to identify the phase through miscibility with a complex whose mesophases were characterised unequivocally by SAXS.

Complexes of $\mathbf{8}$, which have a 3,4-dialkoxyphenylethynyl coligand, all show columnar hexagonal phases $\left(\mathrm{d}_{10}\right.$ and $\mathrm{d}_{11}$ reflections seen in the SAXS data) with the melting and clearing points varying little with terminal chain length to give mesophase ranges of between 18 and $\approx 30{ }^{\circ} \mathrm{C}$. Interestingly, complex 8b showed a more complex mesomorphism with up to three $\mathrm{Col}_{\mathrm{h}}$ phases being observed, two of which appear monotropic. For complexes 9, the first three in the series (9a-9c) showed a $\mathrm{Col}_{\mathrm{r}}$ phase on heating, above which there was a $\mathrm{Col}_{\mathrm{h}}$ phase for 9b and 9c; complex 9d showed a $\mathrm{Col}_{\mathrm{h}}$ phase with a $\mathrm{Col}_{\mathrm{r}}$ phase appearing monotropically. In all cases the nature of the phase was confirmed by SAXS data. Complexes 9b-9d showed some solid-state polymorphism and all melted to the first mesophase at around $78{ }^{\circ} \mathrm{C}$, whereas in 9a melting occurred at the much lower temperature of $55{ }^{\circ} \mathrm{C}$. Clearing points increased significantly from 9a to $9 \mathrm{c}$ (81 to $102{ }^{\circ} \mathrm{C}$ ) and then dropped in 9d $\left(88^{\circ} \mathrm{C}\right)$. The behaviour of these complexes is displayed in Fig. 5 .

\section{Complexes with four terminal chains on the pincer ligand (10 to 13)}

In contrast to complexes $\mathbf{5}$ to $\mathbf{9}$, the phase behaviour of complexes 10 to 13 with four chains on the cyclometallating ligand is rather uniform, inasmuch as they all show a columnar hexagonal phase. Data on transition temperatures are found in Table 2 and are plotted in Fig. 6. The phases were characterised by SAXS data, which showed characteristic $\mathrm{d}_{10}, \mathrm{~d}_{11}$ and, in most cases, $\mathrm{d}_{20}$ reflections (Fig. $7 \mathrm{a}$ and Table $\mathrm{S} 3, \mathrm{ESI} \dagger$ ) and by their characteristic optical textures (Fig. 7b).

The first point of note is that the mesophases are significantly more stable in complexes 10 to 13 with clearing points up to $100{ }^{\circ} \mathrm{C}$ higher than in complexes 5 to 9 (Fig. S5, ESI $\dagger$ ). This is understood by the observation that the periphery of the complexes is better covered by flexible chains (four chains on the pincer ligand) which will in turn give a greater 'cohesion' of the complexes within the columns, so increasing mesophase stability. This explains the depressed phase stability of 10a, as
Table 2 Transition temperatures and enthalpies of complexes 10-13, featuring four chains on the pincer ligand

\begin{tabular}{|c|c|c|c|}
\hline Complex & Transition & $T\left({ }^{\circ} \mathrm{C}\right)$ & $\Delta H\left(\mathrm{~kJ} \mathrm{~mol}^{-1}\right)$ \\
\hline \multirow[t]{2}{*}{$10 a$} & $\mathrm{Cr}-\mathrm{Col}_{\mathrm{h}}$ & 87.7 & 57.7 \\
\hline & $\mathrm{Col}_{\mathrm{h}}-\mathrm{I}^{a}$ & 105.9 & - \\
\hline \multirow[t]{2}{*}{$10 \mathrm{~b}$} & $\mathrm{Cr}-\mathrm{Col}_{\mathrm{h}}$ & 74.0 & 28.8 \\
\hline & $\mathrm{Col}_{\mathrm{h}}-\mathrm{I}^{a}$ & 179.8 & - \\
\hline \multirow[t]{2}{*}{$10 \mathrm{c}$} & $\mathrm{Cr}-\mathrm{Col}_{\mathrm{h}}$ & 71.4 & 62.8 \\
\hline & $\mathrm{Col}_{\mathrm{h}}-\mathrm{I}^{a}$ & 185.0 & - \\
\hline \multirow[t]{2}{*}{$11 \mathrm{a}$} & $\mathrm{Cr}-\mathrm{Col}_{\mathrm{h}}$ & 83.9 & 58.7 \\
\hline & $\mathrm{Col}_{\mathrm{h}}-\mathrm{I}^{a}$ & 172.1 & - \\
\hline \multirow[t]{2}{*}{$11 b$} & $\mathrm{Cr}-\mathrm{Col}_{\mathrm{h}}$ & 77.4 & 75.6 \\
\hline & $\mathrm{Col}_{\mathrm{h}}-\mathrm{I}^{a}$ & 163.2 & - \\
\hline \multirow[t]{2}{*}{$11 \mathrm{c}$} & $\mathrm{Cr}-\mathrm{Col}_{\mathrm{h}}$ & 77.3 & 91.2 \\
\hline & $\mathrm{Col}_{\mathrm{h}}-\mathrm{I}^{a}$ & 147.8 & - \\
\hline \multirow[t]{2}{*}{ 11d } & $\mathrm{Cr}-\mathrm{Col}_{\mathrm{h}}$ & 72.2 & 68.0 \\
\hline & $\mathrm{Col}_{\mathrm{h}}-\mathrm{I}^{a}$ & 189.4 & - \\
\hline \multirow[t]{2}{*}{$12 a$} & $\mathrm{Cr}-\mathrm{Col}_{\mathrm{h}}$ & 83.0 & 85.3 \\
\hline & $\mathrm{Col}_{\mathrm{h}}-\mathrm{I}^{a}$ & 191.2 & - \\
\hline \multirow[t]{2}{*}{$12 b$} & $\mathrm{Cr}-\mathrm{Col}_{\mathrm{h}}$ & 81.0 & 82.1 \\
\hline & $\mathrm{Col}_{\mathrm{h}}-\mathrm{I}^{a}$ & 179.3 & - \\
\hline \multirow[t]{2}{*}{$12 \mathrm{c}$} & $\mathrm{Cr}-\mathrm{Col}_{\mathrm{h}}$ & 77.0 & 73.3 \\
\hline & $\mathrm{Col}_{\mathrm{h}}-\mathrm{I}^{a}$ & 170.7 & - \\
\hline \multirow[t]{2}{*}{ 12d } & $\mathrm{Cr}-\mathrm{Col}_{\mathrm{h}}$ & 80.0 & 103.2 \\
\hline & $\mathrm{Col}_{\mathrm{h}}-\mathrm{I}^{a}$ & 154.5 & - \\
\hline \multirow[t]{3}{*}{$13 a$} & $\mathrm{Cr}-\mathrm{Cr}$ & 44.2 & 50.8 \\
\hline & $\mathrm{Cr}-\mathrm{Col}_{\mathrm{h}}$ & 53.4 & 97.8 \\
\hline & $\mathrm{Col}_{\mathrm{h}}-\mathrm{I}^{a}$ & 187.2 & - \\
\hline \multirow[t]{2}{*}{$13 b$} & $\mathrm{Cr}-\mathrm{Col}_{\mathrm{h}}$ & 58.9 & 62.1 \\
\hline & $\mathrm{Col}_{\mathrm{h}}-\mathrm{I}$ & 195.1 & 4.3 \\
\hline \multirow[t]{3}{*}{$13 \mathrm{c}$} & $\mathrm{Cr}-\mathrm{Col}_{\mathrm{h}}$ & 71.2 & 75.1 \\
\hline & $\mathrm{Col}_{\mathrm{h}}-\mathrm{I}$ & 183.9 & 5.9 \\
\hline & $\left(\mathrm{Col}_{\mathrm{h}}-\mathrm{Lam}\right)$ & (39.4) & (101.2) \\
\hline \multirow[t]{2}{*}{ 13d } & $\mathrm{Cr}-\mathrm{Col}_{\mathrm{h}}$ & 89.0 & 118.9 \\
\hline & $\mathrm{Col}_{\mathrm{h}}-\mathrm{I}$ & 166.0 & 2.8 \\
\hline
\end{tabular}

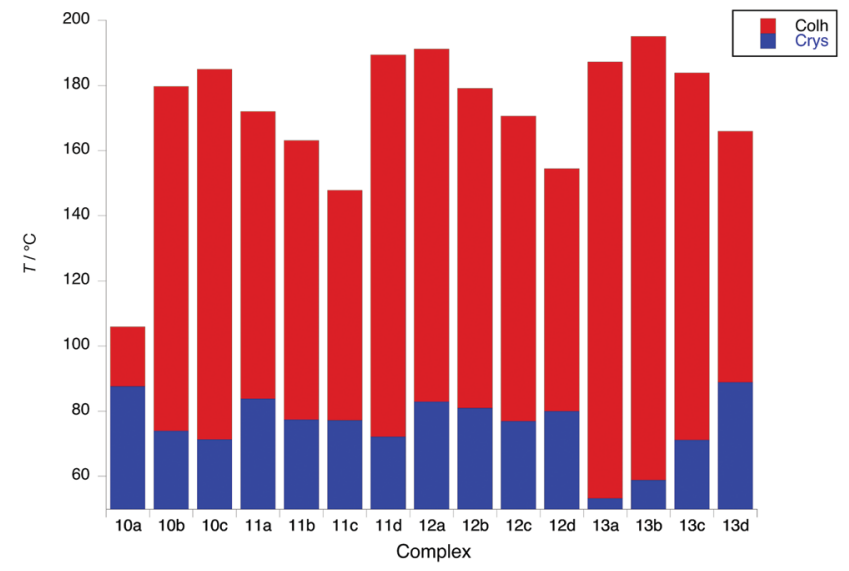

Fig. 6 Transition temperatures and phases for complexes 10 to 13.

in all of the other complexes, the V-like area defined by the pincer ligand and the chains in the 4-positions is filled giving a more disk-like unit that can pack effectively. In general within complexes 11, 12 and 13, there is a decrease in mesophase stability as the chains on the phenylacetylide group increase in length, with a surprisingly enhanced stability observed for 11d. Melting points in complexes $\mathbf{1 1}$ and $\mathbf{1 2}$ vary little, although in 
a

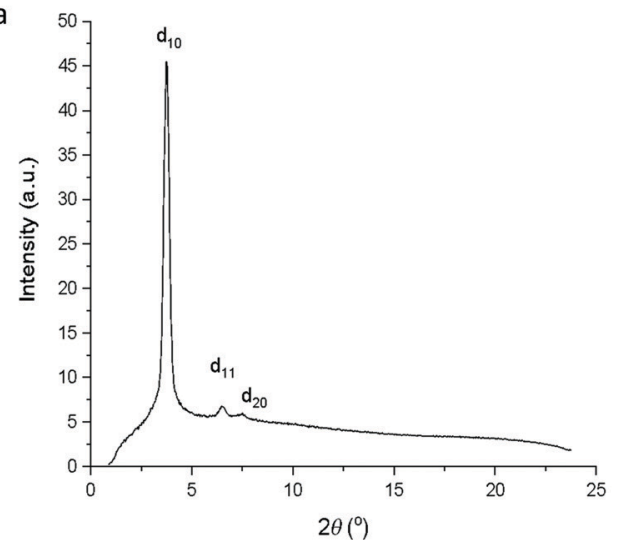

b

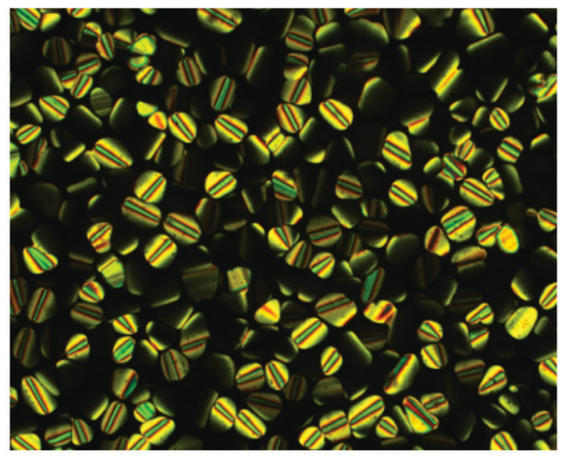

Fig. 7 (a) SAXS pattern for $10 \mathrm{~b}$ at $107^{\circ} \mathrm{C}$ in the $\mathrm{Col}_{\mathrm{h}}$ phase; (b) photomicrograph of $10 \mathrm{~b}$ on cooling at $167^{\circ} \mathrm{C}$ in the $\mathrm{Col} h \mathrm{~h}$ phase.

13 they increase monotonically with the increasing chain length. Interestingly, 12c shows a fairly strongly monotropic phase, identified as lamellar, consistent with the observation of a single reflection in the SAXS data.

Considering the structural data obtained from SAXS, some differences between the two families of complexes are evident. Thus, the hexagonal lattice parameter, $a$, which represents the intercolumnar distance, is consistently greater for complexes $\mathbf{8}$ and 9 than for four-chain analogues 12 and 13. Thus, for 8 and 9, $a$ varies between $36 \AA(n=8)$ and $c a .38 .5 \AA(n=14)$ whereas for $\mathbf{1 2}$ that range is 29.4 to $31.6 \AA$ and for $\mathbf{1 3}$ it is 31 to $33 \AA$. Note that in all cases there is little dependence on the terminal chain length. To account for this difference, it is proposed that complexes $\mathbf{8}$ and $\mathbf{9}$ are more akin to a formal half-disk and so would be likely to associate in a back-to-back fashion similar to the arrangement shown in Fig. 4. This would help fill space better and is a motif that has commonly been proposed for half-disk materials previously. ${ }^{56-58}$ However, for 12 and 13, the extra two chains on the pincer make the complex more intrinsically disk-like so that the repeat unit is effectively a single complex, which is a more compact arrangement, consistent with the structural data. Thus, the solution behaviour does not predict the organisation in the mesophase.

An interesting observation was that with the exception of 13b, 13c and 13d, none of the complexes 10-13 showed a clearing event by differential scanning calorimetry (DSC), even though by microscopy the transition was sharp and readily observable. Where a transition enthalpy could be measured it was small, particularly for columnar phases, with values of 4.3, 5.9 and $2.8 \mathrm{~kJ} \mathrm{~mol}^{-1}$ being found for $13 \mathbf{b}, 13 \mathrm{c}$ and $13 \mathrm{~d}$, respectively, comparable to the data found in complexes $\mathbf{6 - 9}$ (3.9 to $5.8 \mathrm{~kJ} \mathrm{~mol}^{-1}$ ). These data suggest that the columnar phase is quite disordered. Interestingly, SAXS data recorded in the isotropic phase (Fig. 8) showed a broad reflection at around $3.5^{\circ} 2 \theta$, which corresponds to a distance of $c a .25 \AA$. Taken together, these observations suggest that at the clearing point there is a second-order melting of the hexagonal lattice to give a formally isotropic phase in which the columns persist but lose their long-range correlation. This is analogous to the situation found at the clearing points of, for example, chiral nematic,

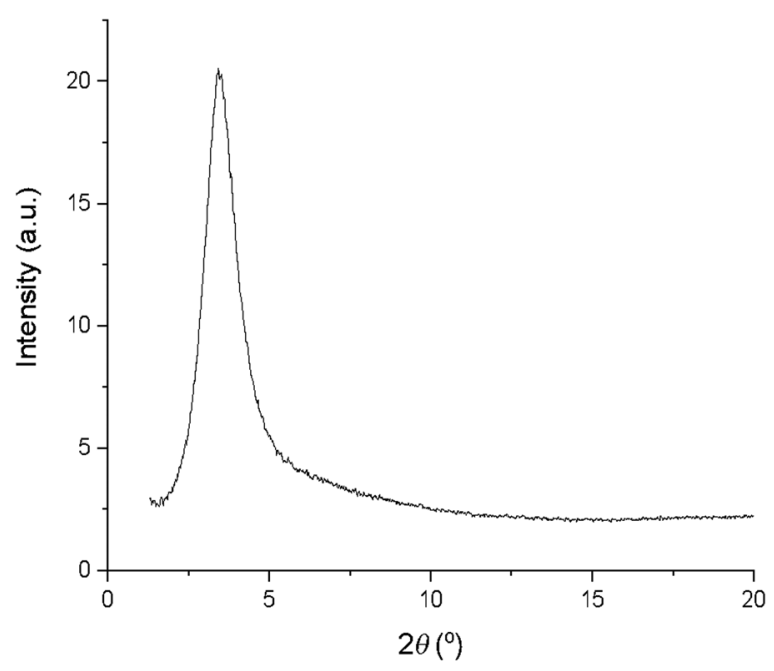

Fig. 8 SAXS pattern of $\mathbf{1 2 b}$ in the isotropic liquid showing a broad reflection in the small-angle region.

cubic and TGB phases as described by Goodby $e t$ al. ${ }^{59}$ where a very similar situation of lattice melting is described. This topic has more recently been re-visited. ${ }^{60}$

\section{Photophysical measurements}

\section{Absorption spectra}

The UV-vis absorption spectra of the complexes were recorded in $\mathrm{CH}_{2} \mathrm{Cl}_{2}$ at room temperature; absorption maxima and corresponding extinction coefficients are summarised in Table 3 . The spectra fall into two categories, those with two chains on the pincer ligand (6 to 9) and those with four (10 to 13). Within these two groups, the spectral profiles are effectively independent of the identity of the arylacetylide ligand.

The effect of the different number of chains on the pincer ligand is exemplified in Fig. 9, which shows the spectra of $\mathbf{6 c}$ and 10c as representative examples with two and four chains, respectively. In $\mathbf{6 c}$, there are three main absorptions, each apparently comprising of a pair of closely separated bands. 
Table 3 Photophysical data for complexes 6 to $13^{a}$

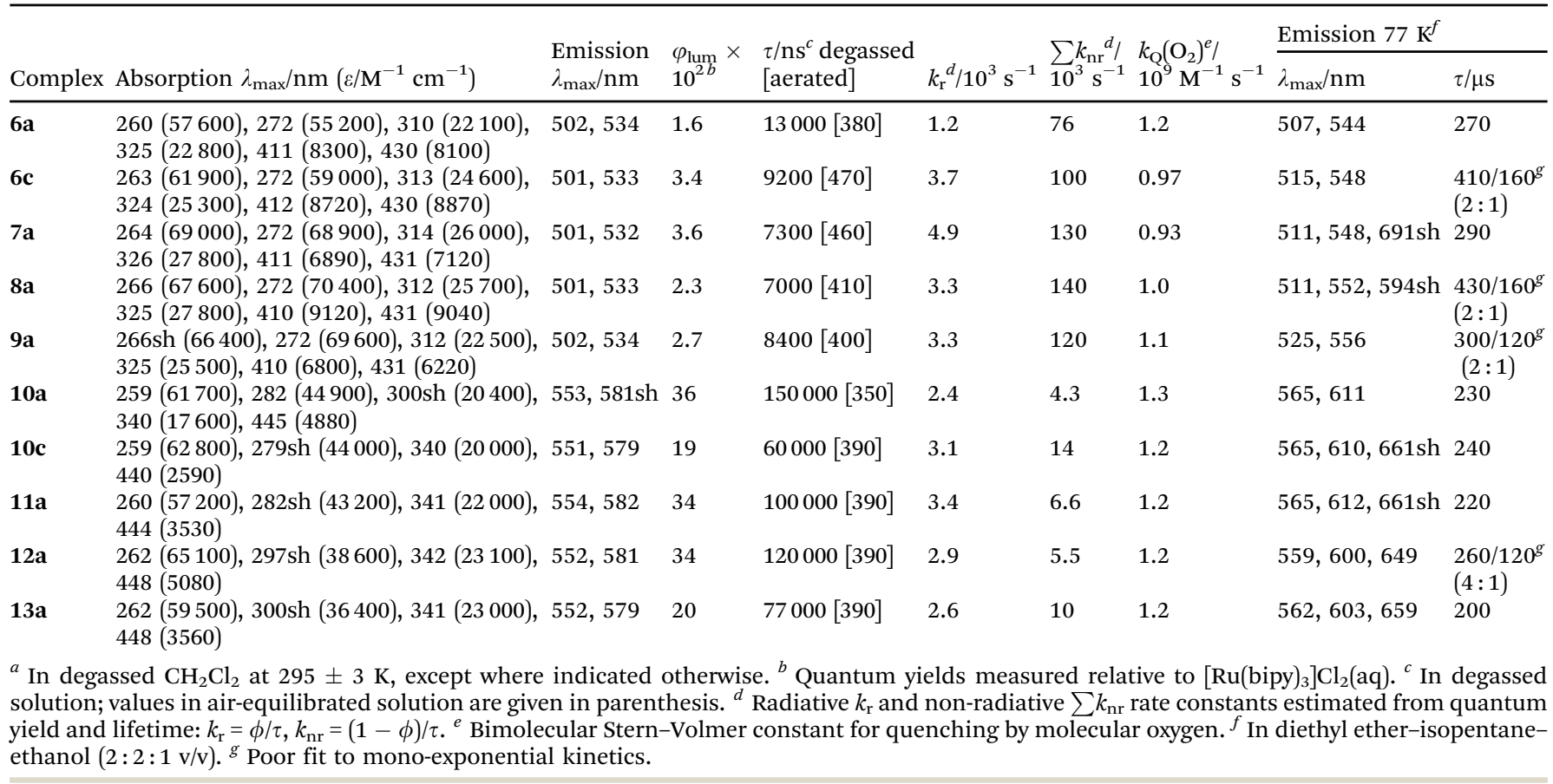
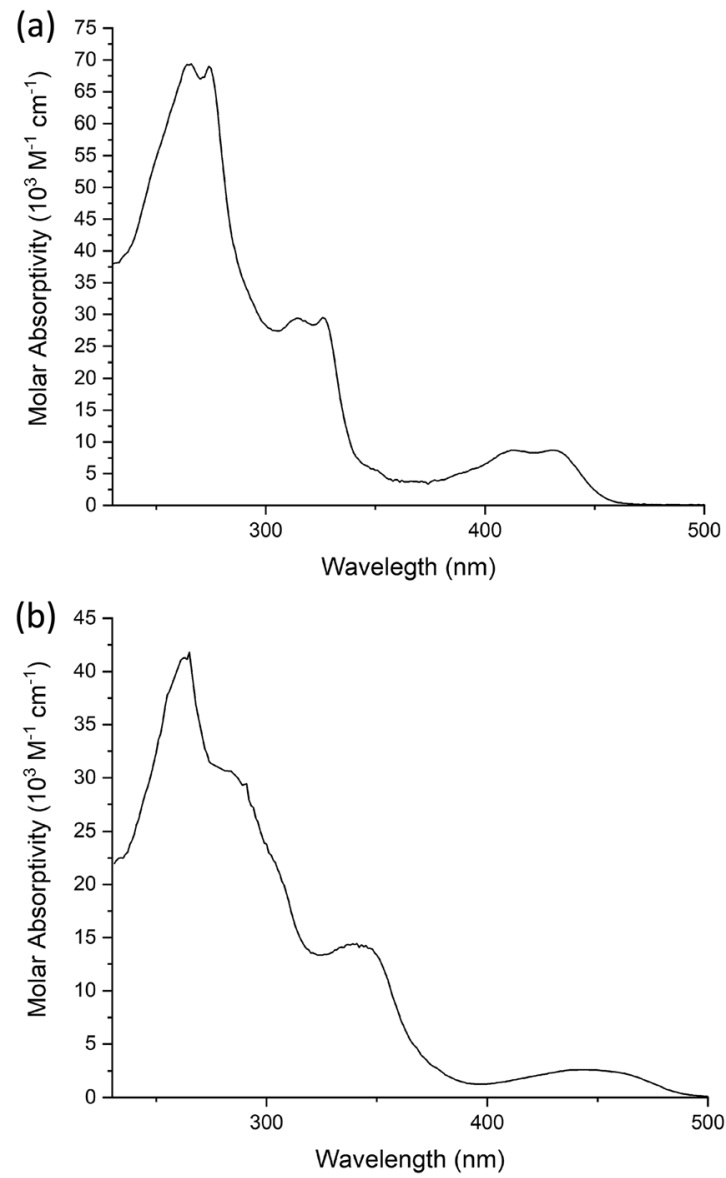

Fig. 9 UV-visible absorption spectra of (a) $6 \mathrm{c}$ and (b) $10 \mathrm{c}$ in $\mathrm{CH}_{2} \mathrm{Cl}_{2}$ at room temperature.
The lowest-energy absorption comprises a band centered at $430 \mathrm{~nm}\left(\varepsilon=8870 \mathrm{M}^{-1} \mathrm{~cm}^{-1}\right)$ and a second transition at $412 \mathrm{~nm}$ of a similar intensity. There are no such bands in the visible region for the proligands, and these bands can be attributed to charge-transfer transitions arising from the introduction of the metal. (Insight into the orbital parentage of transitions giving rise to them is provided by TD-DFT calculations, which are discussed further below: they show that the transitions can be considered to be predominantly LLCT in nature owing to a low contribution of the metal.) At higher energy in the UV region, there are two further, more intense pairs: 324 and $313 \mathrm{~nm}(\varepsilon=$ 25300 and $\left.24600 \mathrm{M}^{-1} \mathrm{~cm}^{-1}\right)$, and 272 and $263 \mathrm{~nm}(\varepsilon=59000$ and $\left.61900 \mathrm{M}^{-1} \mathrm{~cm}^{-1}\right)$. The energy separation within the pairs is around $1100-1300 \mathrm{~cm}^{-1}$, a value consistent with the $\mathrm{C}=\mathrm{N}$ and $\mathrm{C}=\mathrm{C}$ vibrational stretching frequencies of the diphenylpyridine ligand (i.e. excitation to the first and second vibrational levels of the excited states being resolved), and in line with previous studies. ${ }^{20,23,41,53,61}$

The spectra of the complexes with four chains on the pincer ligand are subtly different in that the lowest-energy band is redshifted, its molar absorptivity is reduced significantly and the vibrational structure in all the bands is lost, perhaps indicative of more effective coupling of the excited state with lower-energy vibrations. For 10c as an example (Fig. 9), the lowest energy band is red-shifted to $440 \mathrm{~nm}\left(\varepsilon=2590 \mathrm{M}^{-1} \mathrm{~cm}^{-1}\right)$ with other, more intense absorptions again at shorter wavelengths $340(\varepsilon=$ $\left.20000 \mathrm{M}^{-1} \mathrm{~cm}^{-1}\right)$, 279sh $\left(\varepsilon=44000 \mathrm{M}^{-1} \mathrm{~cm}^{-1}\right)$ and $259(\varepsilon=$ $\left.62800 \mathrm{M}^{-1} \mathrm{~cm}^{-1}\right) \mathrm{nm}$.

\section{Photoluminescence}

The gold(III) precursor complexes 5 and 14 that contain chloride as the monodentate ligand showed no detectable luminescence 
at room temperature. This lack of emission is consistent with literature precedent, which attributes it to deactivation through low-lying d-d excited states. ${ }^{53}$ In contrast, all of the acetylide derivatives 6 to $\mathbf{1 3}$ were phosphorescent in dichloromethane solution at room temperature, appearing green (6-9) or yellow (10-13). The promotion of the emission through the replacement of a chloride ligand by an acetylide is consistent with the $\mathrm{d}-\mathrm{d}$ states being raised in energy by the strongly $\sigma$-donating nature of the acetylide, as also found for many platinum(II) complexes such as those of the form $[\mathrm{Pt}(\mathrm{tpy}) \mathrm{X}]^{+}$. Table 3 lists photophysical data for only a single chain length of each complex type (i.e. the a series where $n=8$, substituent(s) $=$ $\left.-\mathrm{OC}_{8} \mathrm{H}_{17}\right)$ as there was no discernible effect of changing the alkoxy chain length on the emission properties. Spectra and luminescence lifetimes have also been recorded at $77 \mathrm{~K}$ in a transparent glass of composition diethyl ether/isopentane/ethanol $(2: 2: 1 \mathrm{v} / \mathrm{v}$; referred to as EPA).

Complexes 6 to 9 display essentially identical emission spectra to one another in deoxygenated $\mathrm{CH}_{2} \mathrm{Cl}_{2}$ solution at 295 K (Fig. 10 and Table 3). The spectra show clear vibrational structure, with the 0,0 component being the most intense, at $501 \pm 1 \mathrm{~nm}$, and with a vibrational progression of approximately $1200 \mathrm{~cm}^{-1}$. Given that this band is independent of substituents in the alkyne, and with reference to the computational work (below) and literature precedent, the emission is assigned as arising from a metal-perturbed ${ }^{3}\left[\pi \rightarrow \pi^{*}\right]$ intraligand transition based on the diphenylpyridine ligand. ${ }^{20-22,31,41,62}$ The temporal decay of the luminescence fits well to monoexponential kinetics, and the lifetimes are around $8 \mu$ s (Table 3). The emission is strongly quenched in air-equilibrated solution, and lifetimes are reduced under these conditions to around $400 \mathrm{~ns}$. These observations are quite typical of many $\mathrm{Au}^{\mathrm{III}}$ and $\mathrm{Pt}^{\mathrm{II}}$ complexes that emit from triplet excited states. The quantum yields are around 3\%, significantly higher than the related unsubstituted complexes reported by Wong et al., ${ }^{41}$ and are comparable to those of more recently designed gold(III) complexes..$^{20,23,28,34,36,37,41,43}$ There was no significant change in the emission spectral profiles, nor any significant decrease in the lifetimes, on increasing the concentration by an order of magnitude (to around $2 \times 10^{-4} \mathrm{M}$ ). Any aggregation or
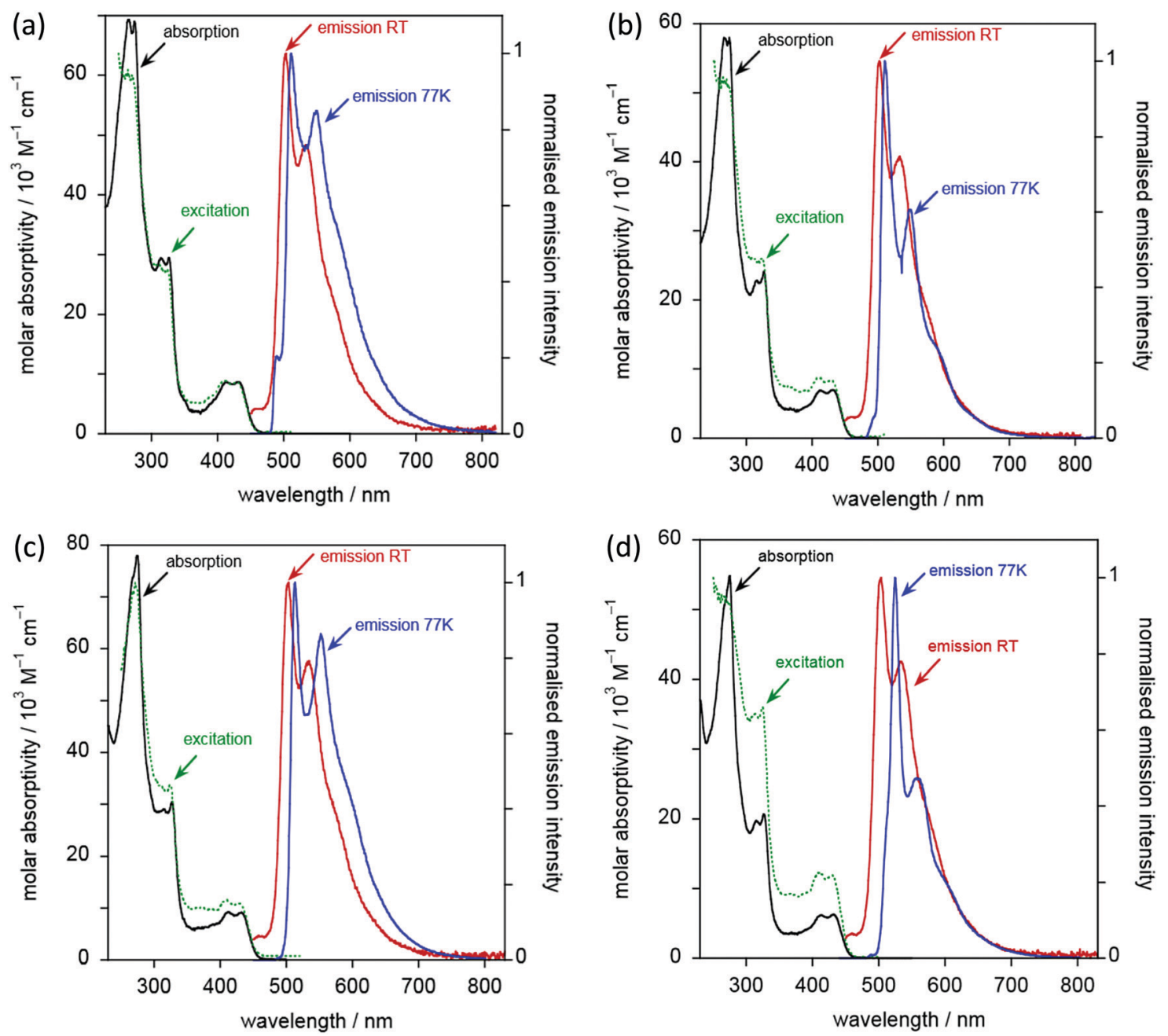

Fig. 10 Absorption spectra (black lines), excitation (dashed green lines), and emission spectra (red lines) for the two-chain complexes (a) $\mathbf{6 c}$, (b) 7a, (c) 8a and (d) $9 \mathrm{a}$ in $\mathrm{CH}_{2} \mathrm{Cl}_{2}$ at $295 \mathrm{~K}$. The emission spectra at $77 \mathrm{~K}$ in EPA are also shown (blue lines). 
intermolecular interactions in the ground or excited state are thus apparently minimal over this range. Only weak and poorly defined emission was detectable in the (neat) solid state, as commonly found for many planar aromatic fluorophores, and also for tripletemitting metal complexes, where microsecond lifetimes facilitate intermolecular excited state annihilation processes.

Although the emission properties are similar for all five complexes (6c and 6a-9a), close inspection of the data in Table 3 suggests a subtle difference for complex $\mathbf{6 a}$, which lacks substituents in the alkynylbenzene unit. It has a rather longer lifetime but a lower quantum yield than $6 \mathbf{c}$ or $7 \mathbf{a}-9$ a. Assuming that the emissive state is formed with unit efficiency, the radiative and non-radiative rate constants, $k_{\mathrm{r}}$ and $\sum k_{\mathrm{nr}}$, can be estimated from the quantum yields and lifetimes (Table 3). These data suggest that $k_{\mathrm{r}}$ is increased by a factor of around 2-4 upon introduction of the substituents, whilst $\sum k_{\mathrm{nr}}$ is only modestly increased, leading overall to the superior quantum yields displayed by the substituted complexes.

At $77 \mathrm{~K}$ (Fig. 10 and Table 3), the vibrational structure becomes more pronounced, and there is a small but definitive red shift. This is unexpected as most metal complexes tend to exhibit a hypsochromic shift on cooling due to the rigidochromic effect, although that is typically most pronounced for complexes that emit from MLCT states. ${ }^{63}$ One possible explanation is the formation of small clusters under low-temperature conditions, through metal-metal interactions: such entropically disfavoured interactions will tend to stabilise the emissive state and thus lead to an apparent red-shift. The temporal decay of emission at $77 \mathrm{~K}$ shows rather poor fits to mono-exponential kinetics; this observation would also be consistent with formation of cluster-like species through intermolecular interactions. However, it might also reflect emission from non-equilibrated, close-lying excited states. Nevertheless, the long lifetimes of several hundred microseconds for the major components suggest that the emission emanates from states that are probably quite heavily localised on the ligand, with only a relatively modest contribution from the metal.

For the five complexes that incorporate four chains on the diphenylpyridine ligand (10c, 10a-13a), the emission spectra are similar to one another (Fig. 11 and Table 3). Their
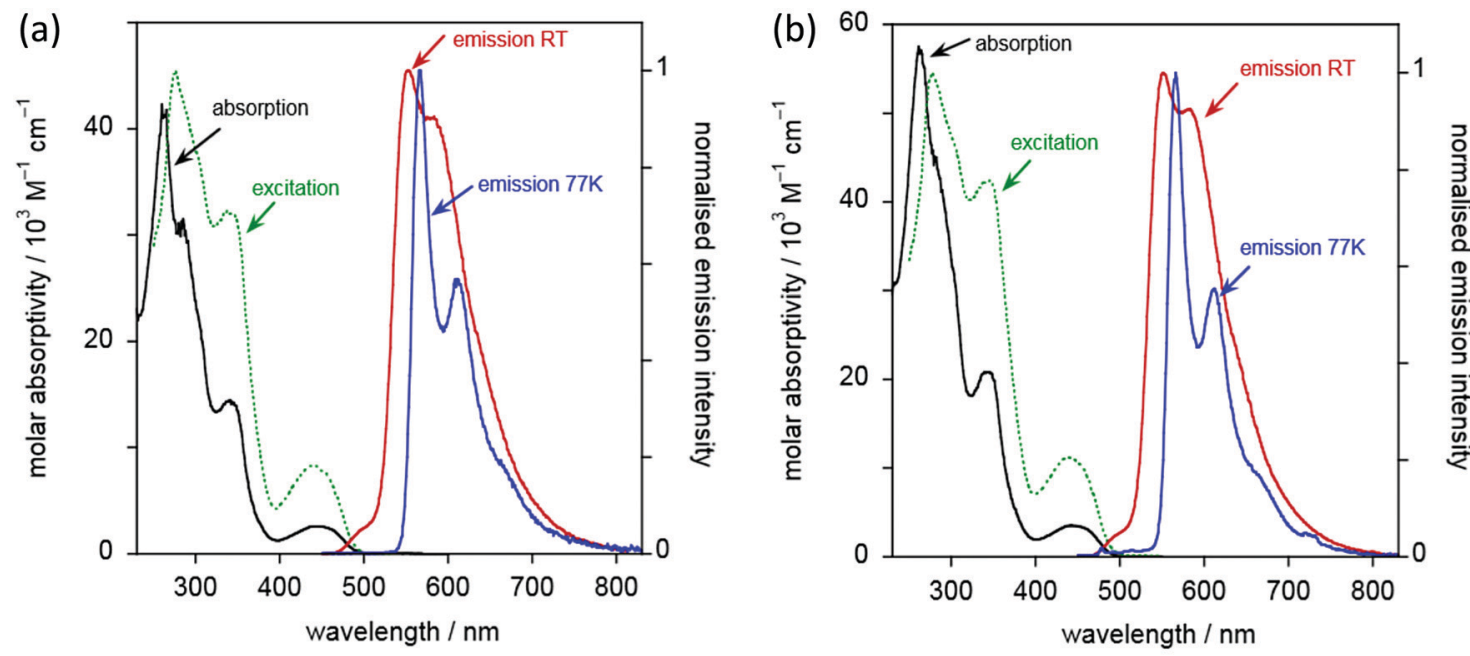

(c)

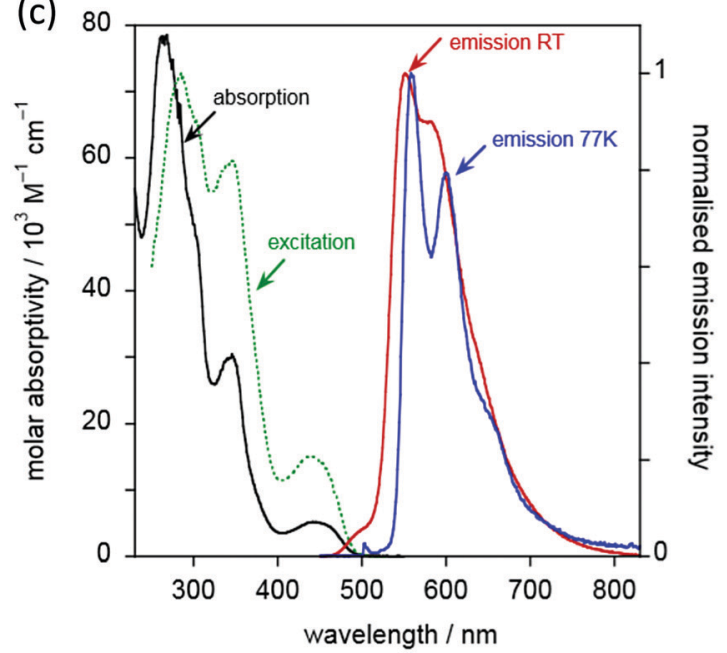

(d)

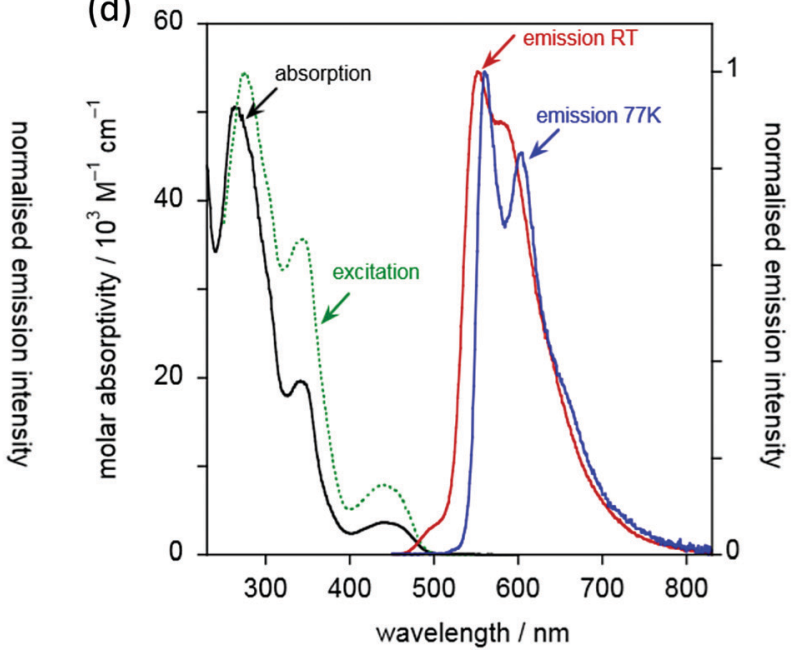

Fig. 11 Absorption spectra (black lines), excitation (dashed green lines), and emission spectra (red lines) for the four-chain complexes (a) 10c, (b) 11a, (c) 12a, and (d) 13a, in $\mathrm{CH}_{2} \mathrm{Cl}_{2}$ at $295 \mathrm{~K}$. The emission spectra at $77 \mathrm{~K}$ in EPA are also shown (blue lines). 

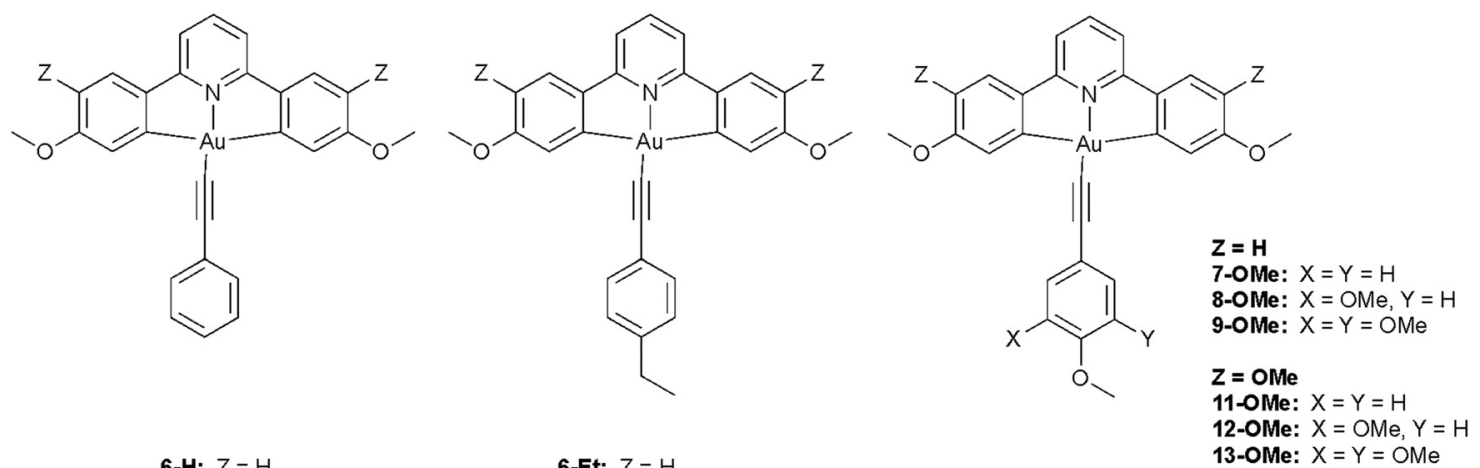

6-H: $\mathrm{Z}=\mathrm{H}$

10-H: $Z=O M e$

6-Et: $Z=\mathrm{H}$

10-Et: $Z=O M e$

Chart 3 Structures of model complexes with truncated alkoxy substituents used for calculations.

emission is red-shifted compared to the two-chain analogues, with $\lambda_{\max }(0,0)$ increased to $553 \pm 2 \mathrm{~nm}$. Vibrational structure is again discernible, though a little less well-resolved than in the two-chain complexes, as was also noted in the absorption spectra. The most dramatic difference between the two series of complexes is, however, the much higher luminescence quantum yields - an order of magnitude greater, reaching as much as $36 \%$. These values are amongst the highest values recorded in the literature for phosphorescent emitters of this type (i.e. $[\mathrm{Au}(\mathrm{CNC})$-acetylide]). Indeed, the vast majority of such complexes of this general design show PLQY values $<10 \%^{21,30,32,42,64,65}$ and, very often, $<1 \%$. ${ }^{20,23,28,34,36,37,41,43}$

The increase in quantum yields is accompanied by longer lifetimes. Indeed, estimation of the $k_{\mathrm{r}}$ and $\sum k_{\mathrm{nr}}$ values (Table 3 ) reveals that the enhanced performance is due to a reduction in the non-radiative decay rate by an order of magnitude compared to the two-chain series. The $k_{\mathrm{r}}$ values, in contrast, are essentially the same for both series. The beneficial effect of inclusion of two further electron-donating alkoxy chains on the pincer ligand, in reducing non-radiative decay processes, can be rationalised readily. As noted, their inclusion decreases the energy of the emissive excited state by around $2000 \mathrm{~cm}^{-1}$ based on the $\lambda_{\max }(0,0)$ values. Thus, the activation energy to populate the deactivating $\mathrm{d}-\mathrm{d}$ states will increase by approximately this magnitude, essentially cutting off this pathway of deactivation at room temperature and leading to the enhanced quantum yields. Amongst the five complexes, there are some small variations in $\varphi$ and $\tau$, with 11a, 12a and the unsubstituted 10a showing the highest values.

At $77 \mathrm{~K}$ in EPA glass, the vibrational structure becomes better resolved. Again, there is an unexpected, small but definite red shift in the spectra compared to those recorded in solution at $295 \mathrm{~K}$. The emission decay at $77 \mathrm{~K}$ for these fourchain complexes fits monoexponential kinetics well (with the possible exception of 12a where a minor shorter component is apparent). The measured lifetimes under these conditions (Table 3) are similar to those of the two-chain series: at this temperature, non-radiative decay via higher-lying $\mathrm{d}-\mathrm{d}$ states will evidently be ruled out even for the two-chain complexes.

\section{Computational chemistry}

Time-dependent density functional theory (TD-DFT) was employed to rationalise the nature of the absorption and emission spectra of the gold acetylide complexes. As the photophysical properties were essentially independent of alkyl chain length, and to aid with computational efficiency, these groups were substituted by either ethyl or methoxy units for the purpose of the calculations. The structures and numbering for these model complexes are shown in Chart 3. The geometries of the complexes were optimised at the BP86/SV(P) level and subsequent single-point energy and TD-DFT calculations were performed using the PBE0 functional with the def2-TZVPP basis set. The composition of the two lowest-energy electronic transitions for each complex are presented in Table 4 and compared to the experimental absorption spectra.

Table 4 Summary of DFT-predicted transitions for simplified versions of complexes 6 to 13. Only transitions with an oscillator strength $>0.001$ and orbital contributions $>10 \%$ are listed $^{a}$

Calculated energy/ Oscillator Transition

Complex $10^{3} \mathrm{~cm}^{-1}\left(\lambda_{\text {calc }} \mid \lambda_{\exp }\right) / \mathrm{nm}$ strength (\% coefficient)

\begin{tabular}{llll}
\hline 6-H & $24.7(406 \mid 430)$ & 0.036 & HOMO $\rightarrow$ LUMO (94) \\
& $25.1(398 \mid 411)$ & 0.148 & HOMO-1 $\rightarrow$ LUMO (96) \\
6-Et & $24.0(417 \mid 430)$ & 0.0476 & HOMO $\rightarrow$ LUMO (95) \\
& $25.1(398 \mid 412)$ & 0.148 & HOMO-1 $\rightarrow$ LUMO (95) \\
7-OMe & $22.7(440 \mid 431)$ & 0.057 & HOMO $\rightarrow$ LUMO (96) \\
& $25.1(397 \mid 411)$ & 0.143 & HOMO-1 $\rightarrow$ LUMO (95) \\
8-OMe & $22.7(441 \mid 431)$ & 0.056 & HOMO $\rightarrow$ LUMO (96) \\
& $25.1(398 \mid 410)$ & 0.142 & HOMO-1 $\rightarrow$ LUMO (95) \\
9-OMe & $22.5(444 \mid 431)$ & 0.047 & HOMO $\rightarrow$ LUMO (96) \\
& $25.1(398 \mid 410)$ & 0.141 & HOMO-2 $\rightarrow$ LUMO (95) \\
10-H & $22.9(438 \mid 445)$ & 0.0707 & HOMO-1 $\rightarrow$ LUMO (50) \\
& & & HOMO $\rightarrow$ LUMO (48) \\
& $24.2(414 \mid 445)$ & 0.0352 & HOMO $\rightarrow$ LUMO (48) \\
& & & HOMO-1 $\rightarrow$ LUMO (46) \\
10-Et & $22.5(445 \mid 440)$ & 0.0545 & HOMO-1 $\rightarrow$ LUMO (93) \\
& $23.9(419 \mid 440)$ & 0.0404 & HOMO $\rightarrow$ LUMO (90) \\
11-OMe & $22.5(445 \mid 444)$ & 0.0516 & HOMO-1 $\rightarrow$ LUMO (92) \\
& $22.8(439 \mid 444)$ & 0.0419 & HOMO $\rightarrow$ LUMO (91) \\
12-OMe & $22.5(445 \mid 448)$ & 0.0520 & HOMO-1 $\rightarrow$ LUMO (95) \\
& $22.9(437 \mid 448)$ & 0.0548 & HOMO $\rightarrow$ LUMO (93) \\
13-OMe & $22.1(452 \mid 448)$ & 0.00290 & HOMO $\rightarrow$ LUMO (93) \\
& $22.5(444 \mid 448)$ & 0.0533 & HOMO-1 $\rightarrow$ LUMO (94)
\end{tabular}

${ }^{a}$ Whilst an approximation, the experimental energy of $S_{1}$ is taken to be the lowest-energy absorption maximum. 


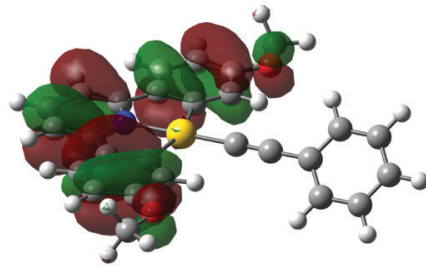

HOMO-1

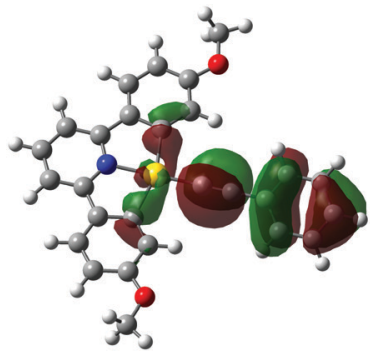

HOMO

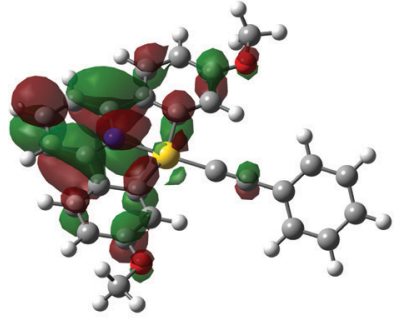

LUMO

Fig. 12 Calculated Kohn-Sham orbitals for complex $\mathbf{6 H}$, isosurface set to the 0.005 level.

The resulting calculations of first singlet excited-state energies are a good match to the experimental data. For the twochain complexes 6-9, two discrete, low-energy transitions corresponding to LUMO $\leftarrow$ HOMO and LUMO $\leftarrow$ HOMO-1 are predicted, separated by between 400 and $2600 \mathrm{~cm}^{-1}$. This might be represented in the observed splitting of the lowest energy band in the experimental spectra, although this observed structure could alternatively be due to excitation to a vibrationally excited level of $S_{1}$.

Examination of the Kohn-Sham orbitals (Fig. 12) indicates that the HOMO-1 is based on the pincer ligand, whereas the HOMO is centered on the acetylide with some gold character. The LUMO is located primarily on the pyridyl ring of the pincer ligand. The energy of the LUMO $\leftarrow$ HOMO transition is reduced by $c a .2000 \mathrm{~cm}^{-1}$ upon incorporation of donor groups into the acetylide ligand (7-OMe, 8-OMe and 9-OMe), which probably arises from an increase in the HOMO energy due to the influence of the donor groups (Fig. 13), and is consistent with the experimentally observed red-shift in the lowest-energy absorption band.

In the case of the four-chain complexes 10-13, the additional alkoxy substituent to the backbone of the CNC ligand raises the energy of the HOMO-1 orbital (Fig. 13) resulting in the LUMO $\leftarrow$ HOMO -1 transition being red shifted by between 2200 and $2700 \mathrm{~cm}^{-1}$ when compared to the two-chain analogues.

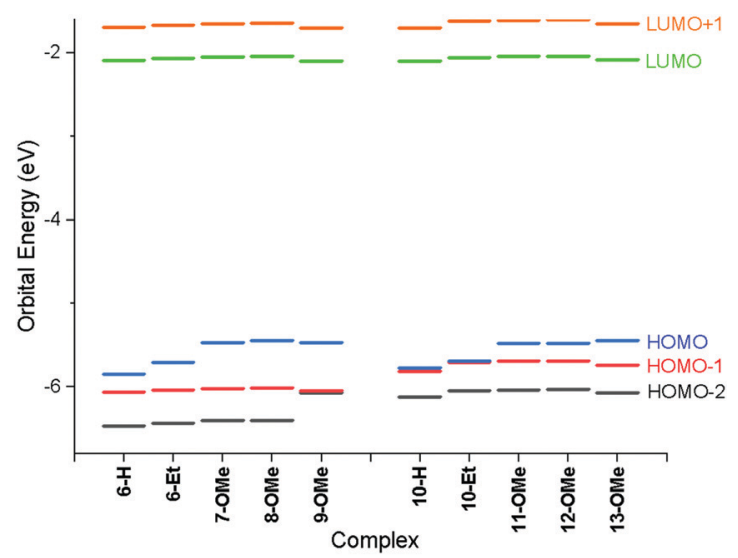

Fig. 13 Energies of frontier molecular orbitals for all species calculated using the PBEO functional with the def2-TZVPP basis set.
In addition to using TD-DFT to determine the singlet excitations, the geometries and energies of the triplet states of complexes 6-H and 10-H were calculated. $\$$ Subtraction of the energy of the corresponding ground state singlet complexes then allowed for the predicted energy of emission to be determined. For 6-H, this was $500 \mathrm{~nm}$, which is in excellent agreement with the experimental value of $502 \mathrm{~nm}$. Likewise, for 10-H, the calculated and experimental values are 548 and $553 \mathrm{~nm}$ respectively.

\section{Device measurements}

Cyclic voltammograms (CV) were recorded to explore the electrochemical properties of the gold complexes and to allow evaluation of the HOMO and LUMO levels. Data for complexes 6a and 10 are shown in Fig. S5 (ESI $\dagger$ ) although experiments performed on other complexes in both series gave the same results; only quasi-reversible reduction potentials were detected for both complexes. Thus, complex 6 a displays a reduction wave with an onset potential of $-1.70 \mathrm{~V}$, while complex 10a presents a reduction with an onset potential of $-1.94 \mathrm{~V}$ (both $v s . \mathrm{Fc} / \mathrm{Fc}^{+}=$ $0.0 \mathrm{~V}$ ). No oxidation process was observed in the accessible window. The energy of the LUMO can be estimated directly from the reduction potential according to the method of Pan et al. ${ }^{66}$ giving values of -2.72 and $-2.48 \mathrm{~V}$ for $6 \mathrm{a}$ and 10a, respectively. In the absence of a measurable oxidation potential, an estimate of the HOMO energy can be obtained by subtracting the optical band gap (in turn estimated from the absorption onset) giving values of -5.41 and $-4.96 \mathrm{~V}$. The higher-lying HOMO of 10a is consistent with the calculations (Fig. 13) and the electron-donating nature of the additional alkoxy chains. These data informed the choice of materials for device fabrication (below).

As noted in the introduction, one potential advantage of liquid-crystalline emitters is that the ordered mesophase offers the possibility for preferred conduction pathways in discotic materials ${ }^{67}$ which could have a beneficial effect on device

$¥$ The nature of the triplet states in gold(III) pincer compounds has been investigated extensively (Chem. Sci., 2015, 6, 3026-3037, Inorg. Chem., 2015, 54, 3624-3630). Although such an approach is beyond the scope of the current study there is a good agreement between our experimental and calculated emission values. 


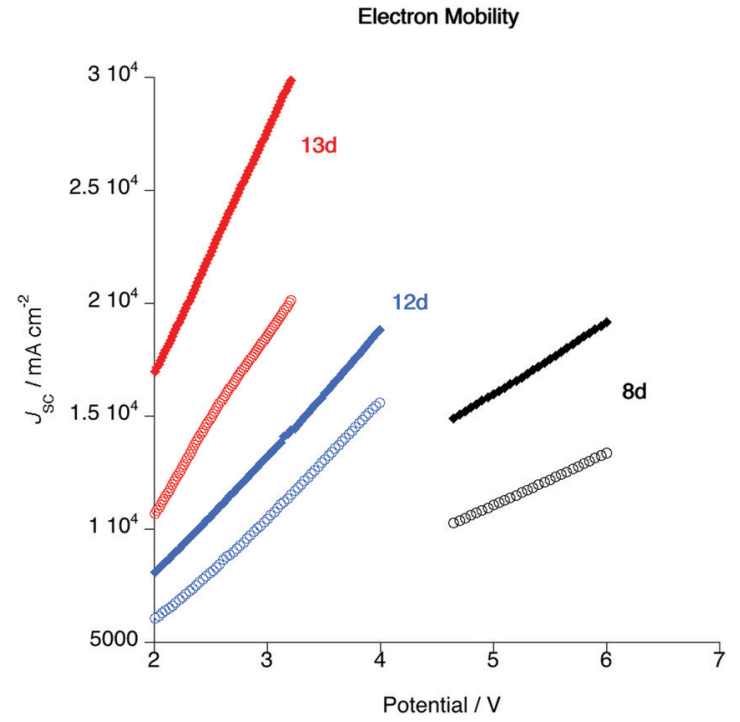

Fig. 14 Plot of current density as a function of applied voltage for complexes $\mathbf{8} \mathbf{d}, \mathbf{1 2} \mathbf{d}$ and $\mathbf{1 3} \mathbf{d}$ in the as-cast state (open circles) and after annealing in the liquid crystal phase (closed diamonds).

characteristics such as drive voltage. In order to test that assertion, the electron mobilities of three complexes $(\mathbf{8 d}, \mathbf{1 2 d}$ and 13d) were evaluated both in the pristine state and after annealing in the liquid-crystalline state. The measurements were made using the SCLC method (see ESI $\dagger$ ) in a device structure of ITO/PEDOT $(30 \mathrm{~nm}) / \mathrm{Au}$ complex $(c a .100 \mathrm{~nm}) /$ $\mathrm{MoO}_{3}(8 \mathrm{~nm}) / \mathrm{Al}(100 \mathrm{~nm})$ and $\mathrm{TIO} / \mathrm{ZnO}(30 \mathrm{~nm}) / \mathrm{Au}$ complex $(c a .100 \mathrm{~nm}) / \mathrm{PFN}-\mathrm{Br}(5 \mathrm{~nm}) / \mathrm{Al}(100 \mathrm{~nm})$. The resulting currentvoltage $(I V)$ characteristics under pulse conditions are shown in Fig. 14 and the mobilities are found as Table 5.

The first important point about these data is that they show that following annealing the electron mobility increases. The process of annealing moved the material into the liquid crystal state and hence into a columnar arrangement giving better overlap of the complex $\pi$-systems. Of course, the annealing process does not create a monodomain sample and so the alignment is by no means perfect, but nonetheless the data demonstrate unequivocally that the mobility is enhanced as a result of liquid crystal organisation. It is then noteworthy that the drive voltage required for complex $\mathbf{8 d}$ is significantly greater than those for 12d and 13d. This observation is consistent with the intercolumnar separations obtained from the SAXS data, which imply that in complexes such as $\mathbf{8 d}$, where there are only

Table 5 Electron mobility data for $\mathbf{8 d}, \mathbf{1 2} \mathbf{d}$ and $\mathbf{1 3 d}$ in the as-cast state (open circles) and after annealing in the liquid crystal phase

\begin{tabular}{|c|c|c|c|c|}
\hline Sample & Condition & $\begin{array}{l}\text { Mobility/ } \\
\mathrm{cm}^{2} \mathrm{~V}^{-1} \mathrm{~s}^{-1}\end{array}$ & $\begin{array}{l}\text { Thickness/ } \\
\text { nm }\end{array}$ & $\begin{array}{l}\text { Processing } \\
\text { temp. } /{ }^{\circ} \mathrm{C}\end{array}$ \\
\hline \multirow[t]{2}{*}{ 8d } & As cast & $1.69 \times 10^{-4}$ & \multirow[t]{2}{*}{120} & 25 \\
\hline & Annealed & $4.05 \times 10^{-4}$ & & 90 \\
\hline \multirow[t]{2}{*}{ 12d } & As cast & $4.68 \times 10^{-4}$ & \multirow[t]{2}{*}{100} & 25 \\
\hline & Annealed & $6.19 \times 10^{-4}$ & & 120 \\
\hline \multirow[t]{2}{*}{ 13d } & As cast & $3.95 \times 10^{-4}$ & \multirow[t]{2}{*}{80} & 25 \\
\hline & Annealed & $5.89 \times 10^{-4}$ & & 120 \\
\hline
\end{tabular}

Table 6 Optimised device data at complex loadings of 5, 10 and $15 \%$ in a host of PVK : OXD-7 (7: 3)

\begin{tabular}{|c|c|c|c|c|c|c|c|}
\hline Complex & $\mathrm{wt} \%$ & $V_{\text {on }} / \mathrm{V}$ & $\begin{array}{l}L_{\max } / \\
\mathrm{cd} \mathrm{m}^{-2}\end{array}$ & $\begin{array}{l}\mathrm{CE}_{\max } / \\
\mathrm{cd} \mathrm{A}^{-1}\end{array}$ & $\begin{array}{l}\mathrm{PE}_{\max } / \\
\operatorname{lm} \mathrm{W}^{-1}\end{array}$ & $\mathrm{EQE}_{\text {max }}$ & $\begin{array}{l}\text { Emission peak/ } \\
\text { nm (CIE } \\
\text { coordinates) }\end{array}$ \\
\hline \multirow[t]{3}{*}{$6 a$} & 5 & 4.0 & 1458 & 22.01 & 12.51 & 6.72 & $508(0.29,0.58)$ \\
\hline & 10 & 4.4 & 1378 & 22.32 & 12.71 & 6.71 & $510(0.31,0.57)$ \\
\hline & 15 & 4.4 & 1004 & 15.23 & 8.37 & 4.58 & $510(0.31,0.58)$ \\
\hline \multirow[t]{3}{*}{$6 c$} & 5 & 4.4 & 1259 & 21.41 & 12.67 & 6.58 & $508(0.31,0.57)$ \\
\hline & 10 & 4.4 & 1370 & 17.31 & 9.69 & 5.24 & $508(0.31,0.56)$ \\
\hline & 15 & 6.0 & 734 & 8.29 & 3.34 & 2.57 & $508(0.31,0.57)$ \\
\hline \multirow[t]{3}{*}{ 8d } & 5 & 4.0 & 1233 & 20.14 & 10.97 & 6.27 & $506(0.32,0.57)$ \\
\hline & 10 & 4.4 & 1229 & 13.76 & 6.97 & 4.25 & $508(0.31,0.57)$ \\
\hline & 15 & 6.8 & 304 & 2.38 & 0.65 & 0.72 & $508(0.30,0.58)$ \\
\hline \multirow[t]{3}{*}{$10 \mathrm{c}$} & 5 & 3.6 & 1765 & 22.53 & 13.41 & 7.14 & $554(0.47,0.52)$ \\
\hline & 10 & 4.0 & 1441 & 21.18 & 11.73 & 6.94 & $556(0.47,0.51)$ \\
\hline & 15 & 4.8 & 1142 & 9.71 & 4.00 & 3.14 & $558(0.48,0.51)$ \\
\hline \multirow[t]{3}{*}{$11 a$} & 5 & 4.0 & 1705 & 21.31 & 12.45 & 6.82 & $554(0.47,0.51)$ \\
\hline & 10 & 4.4 & 1768 & 21.45 & 11.21 & 6.74 & $556(0.47,0.51)$ \\
\hline & 15 & 4.8 & 1261 & 17.59 & 8.92 & 5.57 & $556(0.47,0.51)$ \\
\hline \multirow[t]{3}{*}{ 12d } & 5 & 4.4 & 1401 & 17.14 & 8.94 & 5.52 & $554(0.47,0.51)$ \\
\hline & 10 & 5.2 & 867 & 7.62 & 3.17 & 2.50 & $556(0.47,0.51)$ \\
\hline & 15 & 6.4 & 494 & 4.45 & 1.62 & 1.46 & $556(0.47,0.51)$ \\
\hline \multirow[t]{3}{*}{ 13d } & 5 & 4.4 & 1191 & 18.04 & 10.10 & 5.69 & $554(0.46,0.51)$ \\
\hline & 10 & 4.4 & 1138 & 13.14 & 7.28 & 4.06 & $554(0.47,0.52)$ \\
\hline & 15 & 4.4 & 911 & 11.75 & 6.58 & 3.66 & $554(0.46,0.52)$ \\
\hline
\end{tabular}

two alkoxy chains on the pincer ligand, there is back-to-back overlap of the pincer ligands in the columnar structure. The data also imply that for more inherently disc-like materials such as 12d and 13d, there is greater overlap of the complexes, which would be consistent with the lower drive voltage.

Then to evaluate the electroluminescent (EL) properties of these gold complexes, selected complexes were evaluated as the emitter in OLED devices, chosen to represent the range of complexes studied. Using solution processing, devices with the structure ITO/PEDOT:PSS/emitters/DPEPO/TmPyPB/CsF/ Al§ were fabricated, with the emissive layer being a blend of polymer host (PVK:OXD-7 = 7:3) and the gold complex, the latter at concentrations of 5,10 and $15 \mathrm{wt} \%$. The device configuration and the molecular structures of the materials in the device are shown in Fig. S6 (ESI $\dagger$ ), and the electroluminescence data obtained are collected in Table 6.

After optimisation, devices with $5 \mathrm{wt} \%$ of gold complex were found to give the best results (Fig. S8, ESI $\dagger$ ) and so the electroluminescent (EL) properties are discussed in detail for this loading. Thus, all the devices exhibit intense emission in the range $400-800 \mathrm{~nm}$ (Fig. 15a) and it is of note that the EL emission is dependent on the number of alkoxy chains on the

$\S$ Anode $=$ indium tin oxide; hole injection layer $=$ PEDOT:PSS $($ poly $(3,4-$ ethylenedioxythiophene):polystyrene sulfonate); host = PVK (poly(9-vinylcarbazole)) and OXD-7 (1,3-bis[2-tert-butylphenyl)-1,3,5-oxadiazo-5-yl]benzene); hole/exciton blocking layer = DPEPO (bis[2-(diphenylphosphino)phenyl]ether oxide); electrontransport layer $=$ TmPyPB $(1,3,5$-tris(3-pyridyl-3-phenyl)benzene); electron-injecting layer $=$ cesium fluoride; metal cathode $=$ aluminium . 
(a)

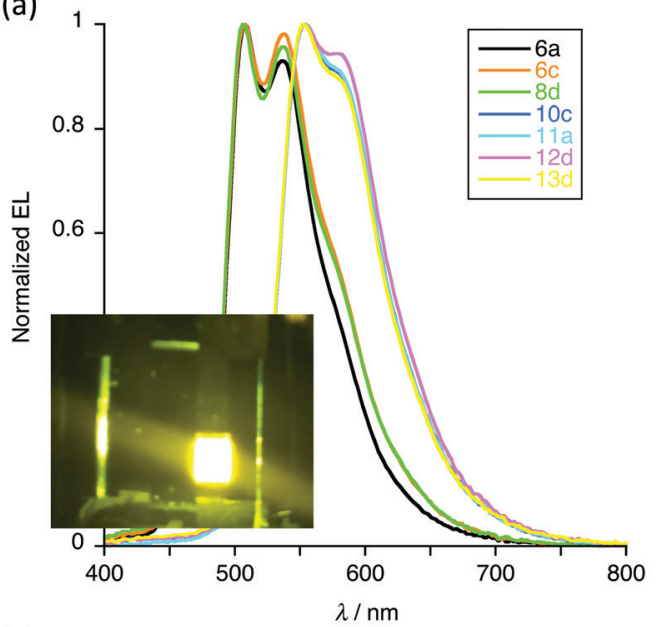

(c)

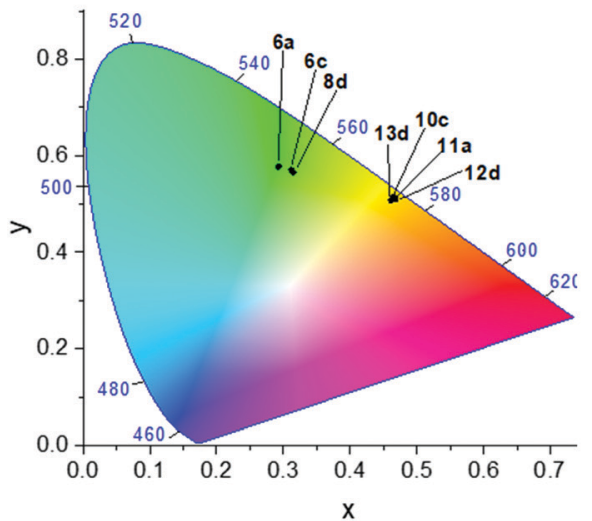

(b)

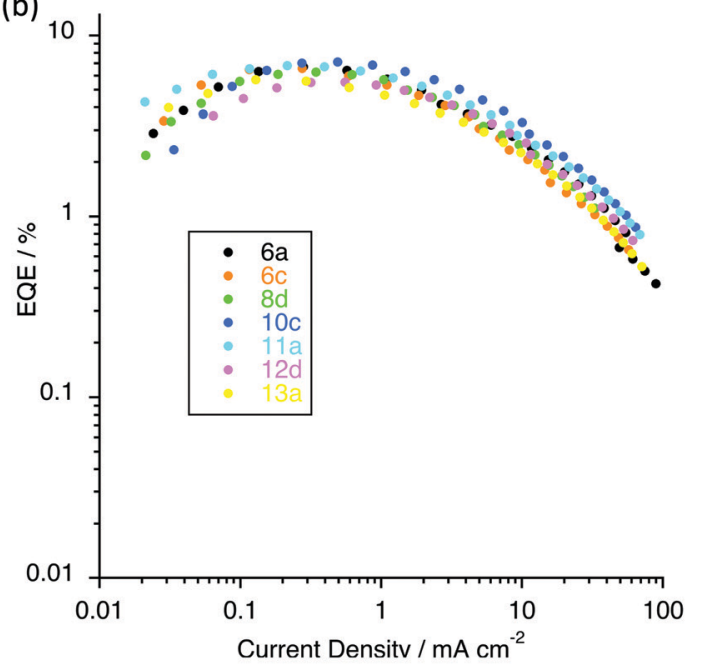

(d)

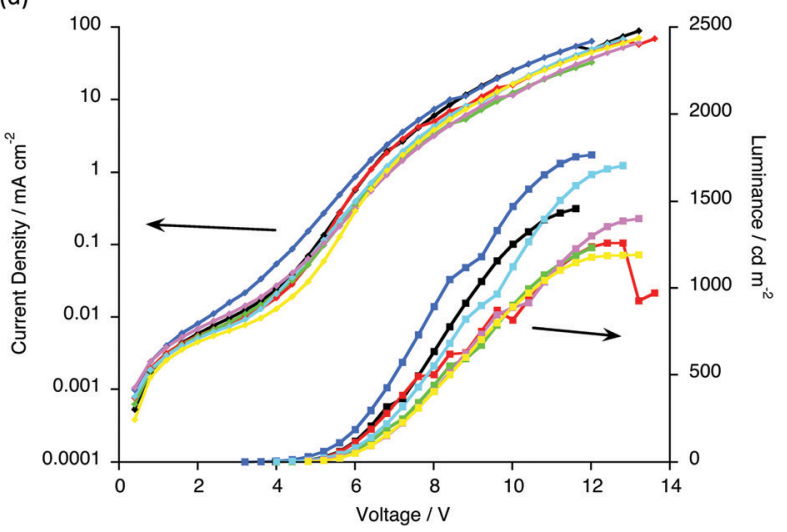

Fig. 15 Device performance: (a) EL spectra with inset photograph of working device; (b) external quantum efficiency (EQE) as a function of current density (c) CIE coordinates; (d) current density and luminance as a function of voltage.

pincer ligand. Devices based on complexes $\mathbf{6 a}, \mathbf{6 c}$ and $\mathbf{8 a}$ show emission maxima at about 508 and $538 \mathrm{~nm}$, in addition to which there is an emission feature at $c a .458 \mathrm{~nm}$ attributed to the host matrix and arising from incomplete energy transfer between host and complex. On the other hand, the devices based on 10c, 11a, 12d and 13d show emission maxima at $554 \mathrm{~nm}$ with a shoulder at about $582 \mathrm{~nm}$ and here there is complete energy transfer between host and the emitters as evidenced by the absence of any higher-energy emissions (Fig. 15a). Compared to complexes $\mathbf{6 a}, \mathbf{6} \mathbf{c}$ and $\mathbf{8 a}$, the presence of the two additional chains on the pincer ligand leads to a redshifted EL emission due to destabilisation of the HOMO, which helps the energy matching with the host matrix.

The CIE coordinates (Fig. 15c) of these devices place them in the green and yellow region of the spectrum, as shown in Fig. 15a. With the increased dopant concentration, there is negligible change in the EL emission, implying the lack of formation of excimers or aggregate that might emit at lower energy.

As shown in Table 6 all devices exhibit relatively low turn-on voltages (at $1 \mathrm{~cd} \mathrm{~m}^{-2}$ ) in the range of 3.6-6.2 $\mathrm{V}$, and satisfactory performance was achieved for the devices. With fewer flexible chains, complexes 6a (two-chain pincer ligand) and 10c (four-chain pincer ligand) showed the best device performance for each 'family'. Thus, devices containing complex 6a gave an EQE of $6.7 \%$ (Fig. 15b), a luminance of $1458 \mathrm{~cd} \mathrm{~m}^{-2}$ (Fig. 15d) and a current efficiency $22.0 \mathrm{~cd} \mathrm{~A}^{-1}$ (Fig. S8, ESI $\dagger$ ), while for complex 10c the same parameters were $\mathrm{EQE}=7.1 \%$, luminance $=1765 \mathrm{~cd} \mathrm{~m}^{-2}$ and current efficiency $=22.5 \mathrm{~cd} \mathrm{~A}^{-1}$. Device performance clearly decreases with the increased dopant concentrations because of the emission quenching at the higher concentrations. This device performance can be considered to be competitive with similar gold(III) complexes for which values ranging from $0.9 \%{ }^{32,36}$ to $15.3 \%{ }^{28}$ are found, the latter of which is the highest reported for a solutionprocessed device based on gold(III) emitters.

\section{Conclusions}

The incorporation of long alkoxy chains into the structure of $\mathrm{Au}(\mathrm{III})$ pincer compounds has a profound effect on their physical properties, notably the nature and stability of the LC phases that are induced are tuned by the substitution pattern of these chains on the pincer ligand. Further, the same structural 
modifications to the both the primary and secondary coordination sphere of the metal complex impart favourable photophysical properties. Thus, having two or four alkoxy chains on the backbone of the pincer ligand results in a bathochromic-shift in the absorption and emission wavelengths, reflecting the influence of the alkoxy groups on the ligand's electronic structure. However, analysis of the photophysical data indicates that modification of the secondary coordination sphere of the metal by placing four alkoxy groups on the pincer ligand also has a significant effect in reducing non-radiative decay processes, reflected in the high quantum yield for emission (up to $36 \%$ ) and the longer lifetimes in this series.

Electron mobility measurements demonstrate that, as expected for disc-like materials in columnar mesophases, the mobility is enhanced in the liquid crystal phase, but in this case the optimum level of the emitter in the device matrix is low (5\%) so that that the beneficial conduction pathways are not accessed. Nonetheless, coupled with the observation that electroluminescent properties are certainly competitive with leading materials in this field, then modification of the primary and secondary coordination sphere of the Au(III) pincer complexes represents an important and dual-pronged strategy to develop and control the materials and photophysical properties of this class of complex.

\section{Experimental}

All experimental data relating to synthesis, single-crystal X-ray structures (cif and cifcheck files), physical measurements, computational chemistry (including methodology and Cartesian coordinates) and device fabrication are found in the ESI. $\dagger$

\section{Dedication}

It is with great pleasure that this paper is dedicated to Professor Emeritus Pablo Espinet from Valladolid, Spain. Liquid crystals and gold have been two of Pablo's abiding interests where he has made seminal contributions over many years. The subject matter of this paper could not then be more appropriate as he moves to his own golden era, within which we wish him good health and great contentment, free from disorder!

\section{Conflicts of interest}

There are no conflicts to declare.

\section{Acknowledgements}

We thank the University of York (RRP) and the EPSRC (computational equipment used in this study, grants EP/H011455/1 and EP/K031589/1) for funding, Johnson Matthey for generous loans of gold salts, the Royal Society and the National Natural Science Foundation of China $(51911530197,51773021)$ for an International Exchange Award (DWB \& YW), Rebecca Howarth for the preparation of some precursor ligands and Alice McEllin for recording some cyclic voltammetry data.

\section{References}

1 X. Wu, M. Zhu, D. W. Bruce, W. Zhu and Y. Wang, J. Mater. Chem. C, 2018, 6, 9848-9860.

2 V. N. Kozhevnikov, B. Donnio and D. W. Bruce, Angew. Chem., Int. Ed., 2008, 47, 6286-6289.

3 V. N. Kozhevnikov, B. Donnio, B. Heinrich and D. W. Bruce, Chem. Commun., 2014, 50, 14191-14193.

4 V. N. Kozhevnikov, B. Donnio, B. Heinrich, J. A. G. Williams and D. W. Bruce, J. Mater. Chem. C, 2015, 3, 10177-10187.

5 C. T. Liao, H. H. Chen, H. F. Hsu, A. Poloek, H. H. Yeh, Y. Chi, K. W. Wang, C. H. Lai, G. H. Lee, C. W. Shih and P. T. Chou, Chem. - Eur. J., 2011, 17, 546-556.

6 A. Santoro, A. C. Whitwood, J. A. G. Williams, V. N. Kozhevnikov and D. W. Bruce, Chem. Mater., 2009, 21, 3871-3882.

7 D. Pucci, I. Aiello, A. Bellusci, A. Crispini, I. De Franco, M. Ghedini and M. La Deda, Chem. Commun., 2008, 2254-2256.

8 D. Pucci, G. Barberio, A. Crispini, O. Francescangeli, M. Ghedini and M. La Deda, Eur. J. Inorg. Chem., 2003, 3649-3661.

9 N. S. S. Kumar, M. Z. Shafikov, A. C. Whitwood, B. Donnio, P. B. Karadakov, V. N. Kozhevnikov and D. W. Bruce, Chem. - Eur. J., 2016, 22, 8215-8233.

10 D. Pucci, G. Barberio, A. Bellusci, A. Crispini, B. Donnio, L. Giorgini, M. Ghedini, M. La Deda and E. I. Szerb, Chem. Eur. J., 2006, 12, 6738-6747.

11 K. Binnemans, J. Mater. Chem., 2009, 19, 448-453.

12 A. M. Prokhorov, A. Santoro, J. A. G. Williams and D. W. Bruce, Angew. Chem., Int. Ed., 2012, 51, 95-98.

13 A. Santoro, A. M. Prokhorov, V. N. Kozhevnikov, A. C. Whitwood, B. Donnio, J. A. G. Williams and D. W. Bruce, J. Am. Chem. Soc., 2011, 133, 5248-5251.

14 E. I. Szerb, A. M. Talarico, I. Aiello, A. Crispini, N. Godbert, D. Pucci, T. Pugliese and M. Ghedini, Eur. J. Inorg. Chem., 2010, 3270-3277.

15 A. M. Talarico, M. Ghedini, C. O. Rossi and E. I. Szerb, Soft Matter, 2012, 8, 11661-11669.

16 Y. Wang, C. P. Cabry, M. Xiao, L. Male, S. J. Cowling, D. W. Bruce, J. Shi, W. Zhu and E. Baranoff, Chem. - Eur. J., 2016, 22, 1618-1621.

17 X. Wu, G. Xie, C. P. Cabry, X. Xu, S. J. Cowling, D. W. Bruce, W. Zhu, E. Baranoff and Y. Wang, J. Mater. Chem. C, 2018, 6, 3298-3309.

18 M. O'Neill and S. M. Kelly, Adv. Mater., 2011, 23, 566-584.

19 Á. Díez, S. J. Cowling and D. W. Bruce, Chem. Commun., 2012, 48, 10298-10300.

20 V. W.-W. Yam, K. M.-C. Wong, L.-L. Hung and N. Zhu, Angew. Chem., Int. Ed., 2005, 44, 3107-3110.

21 V. K.-M. Au, D. P.-K. Tsang, K. M.-C. Wong, M.-Y. Chan, N. Zhu and V. W.-W. Yam, Inorg. Chem., 2013, 52, 12713-12725. 
22 V. K.-M. Au, D. P.-K. Tsang, Y.-C. Wong, M.-Y. Chan and V. W.-W. Yam, J. Organomet. Chem., 2015, 792, 109-116.

23 V. K.-M. Au, K. M.-C. Wong, D. P.-K. Tsang, M.-Y. Chan, N. Zhu and V. W.-W. Yam, J. Am. Chem. Soc., 2010, 132, 14273-14278.

24 V. K.-M. Au, N. Zhu and V. W.-W. Yam, Inorg. Chem., 2013, 52, 558-567.

25 K. T. Chan, G. S. M. Tong, W.-P. To, C. Yang, L. Du, D. L. Phillips and C.-M. Che, Chem. Sci., 2017, 8, 2352-2364.

26 G. Cheng, K. T. Chan, W.-P. To and C.-M. Che, Adv. Mater., 2014, 26, 2540-2546.

27 W.-L. Cheung, S.-L. Lai, M.-C. Tang, C.-H. Lee, M.-Y. Chan and V. W.-W. Yam, J. Mater. Chem. C, 2019, 7, 8457-8464.

28 C.-H. Lee, M.-C. Tang, W.-L. Cheung, S.-L. Lai, M.-Y. Chan and V. W.-W. Yam, Chem. Sci., 2018, 9, 6228-6232.

29 C.-H. Lee, M.-C. Tang, Y.-C. Wong, M.-Y. Chan and V. W.-W. Yam, J. Am. Chem. Soc., 2017, 139, 10539-10550.

30 S. K.-L. Siu, C. Y.-S. Chung and V. W.-W. Yam, J. Organomet. Chem., 2017, 845, 177-188.

31 S. K.-L. Siu, C. Po, K.-C. Yim, V. K.-M. Au and V. W.-W. Yam, CrystEngComm, 2015, 17, 8153-8162.

32 M.-C. Tang, C. K.-M. Chan, D. P.-K. Tsang, Y.-C. Wong, M. M.-Y. Chan, K. M.-C. Wong and V. W.-W. Yam, Chem. Eur. J., 2014, 20, 15233-15241.

33 M.-C. Tang, C.-H. Lee, M. Ng, Y.-C. Wong, M.-Y. Chan and V. W.-W. Yam, Angew. Chem., Int. Ed., 2018, 57, 5463-5466.

34 M.-C. Tang, M.-Y. Leung, S.-L. Lai, M. Ng, M.-Y. Chan and V. Wing-Wah Yam, J. Am. Chem. Soc., 2018, 140, 13115-13124.

35 M.-C. Tang, D. P.-K. Tsang, M. M.-Y. Chan, K. M.-C. Wong and V. W.-W. Yam, Angew. Chem., Int. Ed., 2013, 52, 446-449.

36 M.-C. Tang, D. P.-K. Tsang, M.-Y. Chan, K. M.-C. Wong and V. W.-W. Yam, Mater. Chem. Front., 2017, 1, 2559-2568.

37 M.-C. Tang, D. P.-K. Tsang, Y.-C. Wong, M.-Y. Chan, K. M.-C. Wong and V. W.-W. Yam, J. Am. Chem. Soc., 2014, 136, 17861-17868.

38 W.-P. To, K. T. Chan, G. S. M. Tong, C. Ma, W.-M. Kwok, X. Guan, K.-H. Low and C.-M. Che, Angew. Chem., Int. Ed., 2013, 52, 6648-6652.

39 W.-P. To, D. Zhou, G. S. M. Tong, G. Cheng, C. Yang and C.-M. Che, Angew. Chem., Int. Ed., 2017, 56, 14036-14041.

40 B. Y.-W. Wong, H.-L. Wong, Y.-C. Wong, M.-Y. Chan and V. W.-W. Yam, Angew. Chem., Int. Ed., 2017, 56, 302-305.

41 K. M.-C. Wong, L.-L. Hung, W. H. Lam, N. Zhu and V. W.-W. Yam, J. Am. Chem. Soc., 2007, 129, 4350-4365.

42 K.-C. Yim, V. K.-M. Au, L.-L. Hung, K. M.-C. Wong and V. W.-W. Yam, Chem. - Eur. J., 2016, 22, 16258-16270.

43 K.-C. Yim, V. K.-M. Au, K. M.-C. Wong and V. W.-W. Yam, Chem. - Eur. J., 2017, 23, 5772-5786.

44 K.-C. Yim, E. S.-H. Lam, K. M.-C. Wong, V. K.-M. Au, C.-C. Ko, W. H. Lam and V. W.-W. Yam, Chem. - Eur. J., 2014, 20, 9930-9939.

45 D. Zhou, W.-P. To, Y. Kwak, Y. Cho, G. Cheng, G. S. M. Tong and C.-M. Che, Adv. Sci., 2019, 0, 1802297.
46 C.-H. Lee, M.-C. Tang, F. K.-W. Kong, W.-L. Cheung, M. Ng, M.-Y. Chan and V. W.-W. Yam, J. Am. Chem. Soc., 2020, 142, 520-529.

47 D. Zhou, W.-P. To, Y. Kwak, Y. Cho, G. Cheng, G. S. M. Tong and C.-M. Che, Adv. Sci., 2019, 6, 1802297.

48 D. Zhou, W.-P. To, G. S. M. Tong, G. Cheng, L. Du, D. L. Phillips and C.-M. Che, Angew. Chem., Int. Ed., 2020, 59, 6375-6382.

49 H. Beucher, S. Kumar, E. Merino, W.-H. Hu, G. Stemmler, S. Cuesta-Galisteo, J. A. González, J. Jagielski, C.-J. Shih and C. Nevado, Chem. Mater., 2020, 32, 1605-1611.

50 L.-K. Li, M.-C. Tang, S.-L. Lai, M. Ng, W.-K. Kwok, M.-Y. Chan and V. W.-W. Yam, Nat. Photonics, 2019, 13, 185-191.

51 S. Coco and P. Espinet, in Gold Chemistry, ed. F. Mohr, Wiley, 2009, ch. 8, pp. 357-396.

52 R. Chico, E. de Domingo, C. Domínguez, B. Donnio, B. Heinrich, R. Termine, A. Golemme, S. Coco and P. Espinet, Chem. Mater., 2017, 29, 7587-7595.

53 K.-H. Wong, K.-K. Cheung, M. C.-W. Chan and C.-M. Che, Organometallics, 1998, 17, 3505-3511.

54 A. F. Suleymanova, O. S. Eltsov, D. N. Kozhevnikov, A. O. Lantushenko, M. P. Evstigneev and V. N. Kozhevnikov, ChemistrySelect, 2017, 2, 3353-3355.

55 L. Ciano, N. Fey, C. J. V. Halliday, J. M. Lynam, L. M. Milner, N. Mistry, N. E. Pridmore, N. S. Townsend and A. C. Whitwood, Chem. Commun., 2015, 51, 9702-9705.

56 R. Atencio, J. Barbera, C. Cativiela, F. J. Lahoz, J. L. Serrano and M. M. Zurbano, J. Am. Chem. Soc., 1994, 116, 11558-11559.

57 C. K. Lai, A. G. Serrette and T. M. Swager, J. Am. Chem. Soc., 1992, 114, 7948-7949.

58 F. Morale, R. W. Date, D. Guillon, D. W. Bruce, R. L. Finn, C. Wilson, A. J. Blake, M. Schröder and B. Donnio, Chem. Eur. J., 2003, 9, 2484-2501.

59 J. W. Goodby, D. A. Dunmur and P. J. Collings, Liq. Cryst., 1995, 19, 703-709.

60 J. W. Goodby, R. J. Mandle, E. J. Davis, T. Zhong and S. J. Cowling, Liq. Cryst., 2015, 42, 593-622.

61 V. K.-M. Au, K. M.-C. Wong, N. Zhu and V. W.-W. Yam, J. Am. Chem. Soc., 2009, 131, 9076-9085.

62 K. M.-C. Wong, X. Zhu, L.-L. Hung, N. Zhu, V. W.-W. Yam and H.-S. Kwok, Chem. Commun., 2005, 2906-2908.

63 A. J. Lees, Comments Inorg. Chem., 1995, 17, 319-346.

64 J. Fernandez-Cestau, B. Bertrand, A. Pintus and M. Bochmann, Organometallics, 2017, 36, 3304-3312.

65 M.-C. Tang, C.-H. Lee, S.-L. Lai, M. Ng, M.-Y. Chan and V. W.-W. Yam, J. Am. Chem. Soc., 2017, 139, 9341-9349.

66 L. Pan, B. Hu, X. Zhu, X. Chen, J. Shang, H. Tan, W. Xue, Y. Zhu, G. Liu and R.-W. Li, J. Mater. Chem. C, 2013, 1, 4556-4564.

67 T. Wöhrle, I. Wurzbach, J. Kirres, A. Kostidou, N. Kapernaum, J. Litterscheidt, J. C. Haenle, P. Staffeld, A. Baro, F. Giesselmann and S. Laschat, Chem. Rev., 2016, 116, 1139-1241. 